\begin{tabular}{|c|c|c|c|}
\hline Eiszeitalter u. Gegenwart & $\mathbf{4 8}$ & $\begin{array}{c}133-161 \\
5 \mathrm{Abb} ., 4 \mathrm{Tab} .\end{array}$ & Hannover 1998 \\
\hline
\end{tabular}

\title{
Interpretation pflanzlicher Reste aus holozänen Auensedimenten am Beispiel von drei Bohrkernen des Wettertales (Hessen)
}

\author{
Angela Kreuz, Sabine Nolte, Astrid StobBE*)
}

Holocene, fluvial environment, loess landscape, plant remains, human impact

Wetter valley, Wetterau/Hessen

\begin{abstract}
Kurzfassung: Zur Rekonstruktion der holozänen Landschaftsentwicklung eines kleinen Flußeinzugsgebietes in der Wetterau (Hessen) wurden Sedimentkerne erbohrt und mit verschiedenen Methoden untersucht. Hier werden die botanischen Ergebnisse von drei Bohrkernen aus dem Wettertal vorgestellt. Da die Pollenanalysen eher die regionale Vegetation, die botanischen Großreste hingegen eher die lokale oder extralokale Vegetation widerspiegeln, ist ein möglichst vollständiges Bild der holozänen Vegetationsentwicklung am besten durch eine Kombination beider Methoden zu erreichen. Neben einigen Aspekten zur Bildung des sogenannten Schwarzen Auenbodens und holozäner Auenlehme ergaben sich Hinweise auf (u. a. mesolithische) anthropogene Aktivitäten im Tal der Wetter.
\end{abstract}

\section{[On the interpretation of botanical material in Holocene alluvial sediments from three cores of the Wetter catchment (Hessen, Germany)]}

Abstract: In order to reconstruct the Holocene landscape evolution of a relatively small catchment area in the Wetterau (Hessen), alluvial sediments were retrieved and analysed using various methods. Presented here are the results of the interpretation of botanical macro remains and pollen/spores from three Holocene cores taken in the Wetter valley. The data show that a complete picture of the vegetation of the area during the Holocene is best achieved using both methods, since the pollen content reflects the regional vegetation, whereas the macro remains give a more detailed account of the local vegetation in the river valley. Apart from some aspects concerning the formation of the so-called black meadow soil (Schwarzer Auenboden) and Holocene flood loams, indication of (e.g. Mesolithic) human activities in the Wetter-valley was found.

\section{Inhalt}

1 Einleitung (A. Kreuz \& S. Nolte)

2 Die Bohrkerne und ihre Datierung

(S. NOLTE)

\footnotetext{
*) Anschriften der Verfasserinnen: Dr. A. Kreuz, Inst. der Komm. für Archäologische Landesforschung in Hessen, Archäobotanische Abteilung, Schloß Biebrich/Ostflügel, 65203 Wiesbaden; Dipl.-Geogr. S. Nolte, Am Grün 56a, 35037 Marburg/L; Dr. A. StobBE, Seminar f. Vor- u. Frühgeschichte, Arndtstr. 11, 60325 Frankfurt.
}

3 Ergebnisse der botanischen Großrestanalysen (A. Kreuz)

3.1 Zur Methode

3.2 Süßwasser- und Moorvegetation stehender oder langsam fließender Gewässer

3.3 Krautige Vegetation oft gestörter Plätze

3.4 Feuchtwiesen und Bachuferfluren

3.5 Waldnahe Staudenfluren, Gebüsche und Wälder

3.6 Arten trockener Standorte

3.7 Kulturpflanzen und Beikräuter

4 Pollenanalytische Ergebnisse (A. Sтовве)

4.1 Methode

4.2 Auswertung

5 Vergleich der Großrest- und Pollenanalysen (A. Kreuz \& A. STOBве)

6 Mesolithische Besiedlungsspuren? (A. Kreuz)

7 Schriftenverzeichnis

\section{Einleitung}

(A. Kreuz \& S. Nolte)

Die hier vorgestellten Untersuchungen sind innerhalb des seit 1993 bestehenden DFG-Schwerpunktprogramms „Wandel der Geo-Biosphäre während der letzten 15.000 Jahre - Kontinentale Sedimente als Ausdruck sich verändernder Umweltbedingungen" im Rahmen des von W. ANDRES und J. Wunderlich geleiteten Projektes „Auenund Talrandsedimente in der nördlichen Wetterau und im Amöneburger Becken als Indikatoren für sich verändernde Umweltbedingungen im Spätpleistozän und Holozän" durchgeführt worden. Dabei konnten durch interdisziplinäre $\mathrm{Zu}$ sammenarbeit von Wissenschaftlerinnen der Botanik und Geographie Sedimente eines Fließgewässers (Wetter) in der Wetterau untersucht und zeitlich eingeordnet werden (Abb. 1). Durch detaillierte prozeß- und milieuspezifische Analysen der Auen- und Talrandsedimente sollte ein möglichst vollständiges Bild der spätpleistozänen und holozänen Entwicklung sowie des anthropo- 


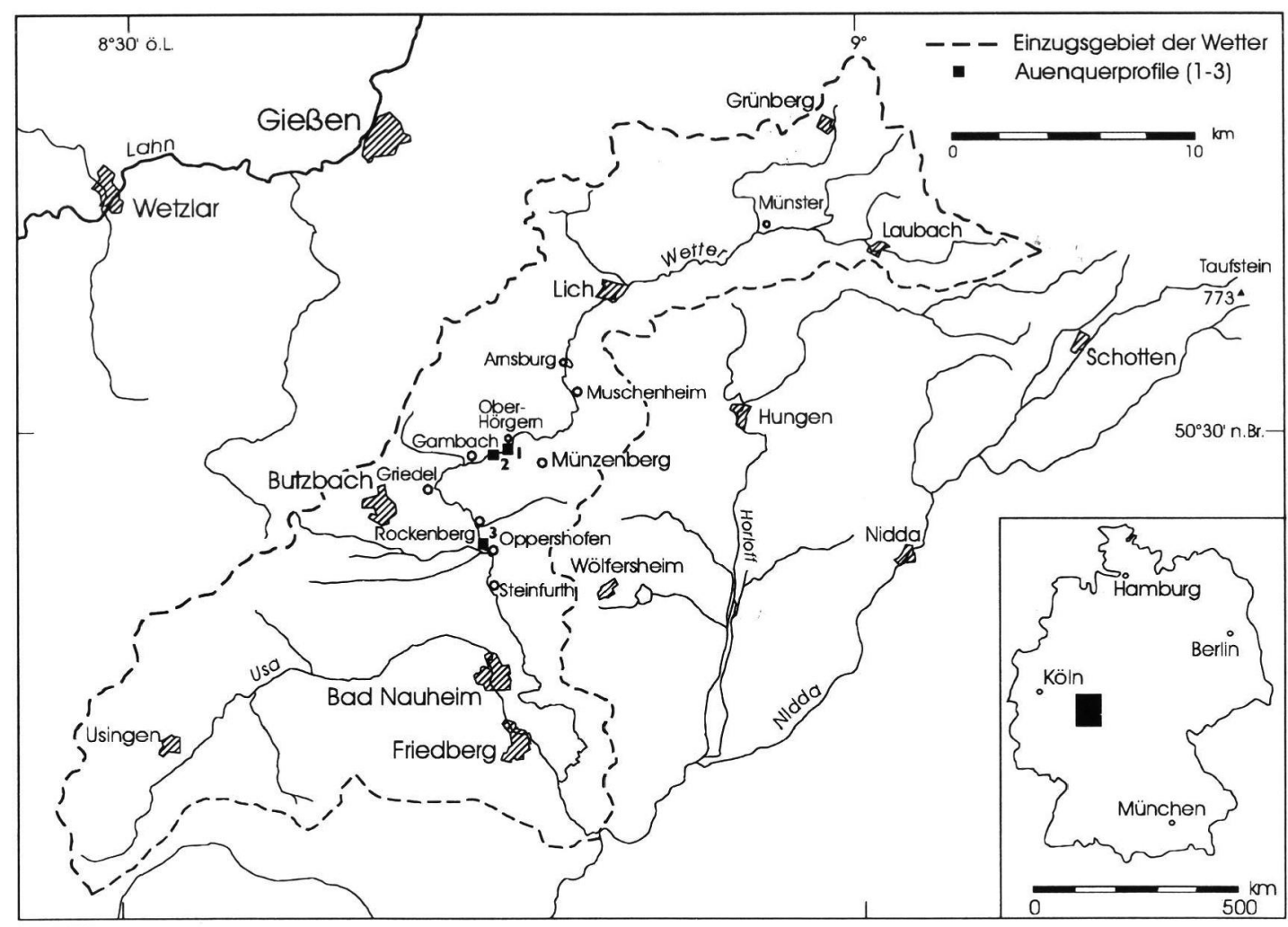

Abb. 1: Arbeitsgebiet und Lage der Auenquerprofile im Tal der Wetter (aus NolTE in Vorber.).

Fig. 1: Field area and location of cross-sections in the Wetter valley (from NolTe in prep.).

genen Anteils der Veränderungen entstehen. Von besonderem Interesse ist in diesem Zusammenhang die Erforschung eines kleineren fluvialen Einzugsgebietes von $520 \mathrm{~km}^{2}$ (HESS. MIN. F. LANDW. U. FORST. 1968). Zu einem späteren Zeitpunkt wird innerhalb des SPP ein Vergleich mit den Ergebnissen aus anderen Flußtälern (z. B. Ohm, Lahn, Main) möglich sein (NoLTE in Vorber.). Da im Wettertal künstliche Aufschlüsse (Kiesgruben o. ä.) fehlen, mußten die Sedimente durch Bohrungen erschlossen werden (Kap. 2).

Die Wetterau ist eine flachwellige Beckenlandschaft und umfaßt nach SABEL (1982) etwa 800 $\mathrm{km}^{2}$. Sie erstreckt sich zwischen dem devonischen Taunus im Westen und dem tertiären Vogelsberg im Osten ca. $40 \mathrm{~km}$ in nord-südlicher Richtung und ist durchschnittlich $20 \mathrm{~km}$ breit. Infolge tertiärer Absenkung bilden Kiese, Sande, Kalke und Mergel die Beckenfüllung. Kleinere Basaltvorkommen sind Ausläufer des Vogelsberges. Die gesamte Wetterau wurde im Pleistozän von bis zu 15 m mächtigem Löß überdeckt. Bis ca. 230 bis $250 \mathrm{~m}$ ü. NN bildet er noch immer das Ausgangssubstrat der Bodenbildung. Oberhalb und an Steilhängen dominieren Schuttdecken, umgelagerter Löß und Lößlehm (SABEL 1982). Die vorherrschenden Böden sind in der Wetterau heute Schwarzerderelikte bzw. alle Übergangsstadien zwischen degradierten Schwarzerden und Parabraunerden (SABEL 1982; SCHRAdER 1978). In den Auen überwiegen Auengleye und Braune Auenböden, an den Hängen der Flußtäler, vor allem in Unterhangbereichen, Kolluvien.

Die im Regenschatten des Taunus gelegene Wetterau stellt als trocken-warme Landschaft (ca. 550 mm Jahresniederschag; $9^{\circ} \mathrm{C}$ Jahresdurchschnittstemperatur) mit vorwiegend Süd-West-Winden einen klimatischen Gunstraum dar (DEUTSCHER WETTERDIENST 1950), was sich in einer intensiven agrarischen Nutzung während der gesamten Vor- und Frühgeschichte äußert (u. a. Rupp 1991). Das Wettertal ist heute von spätglazialen und holozänen Sedimenten bis zu maximal acht Meter aufgefüllt. Wie bereits von Hiller et al. (1991: 26) bemerkt, erscheinen die Flußtäler auf geologischen Karten als wenig differenzierte Einheiten, die ihrer wechselvollen Entstehung und ihrem Aufbau nicht gerecht werden (vgl. Kap. 2). Niederterrassen und Talauen lassen sich im Untersuchungsgebiet geomorphologisch zumeist nicht 
trennen. Drei Auenquerprofile konnten von S. NolTE mittels Pürckhauer-Bohrungen rekonstruiert werden, die im Abstand von ca. 15 m niedergebracht wurden. Die Auenquerprofile liegen in der nördlichen Wetterau 0,5 bis $4 \mathrm{~km}$ voneinander entfernt zwischen 141 und $148 \mathrm{~m}$ ü. NN (Abb. 1-4). Als Arbeitsgebiet wurde der Mittellauf des Wettertales ausgewählt, da hier Talabschnitte mit einer möglichst stetig fortschreitenden Sedimentation und einer möglichst vollständigen holozänen Abfolge zu erwarten waren.

\section{Die Bohrkerne und ihre Datierung}

(S. NOlTE)

Zur zusätzlichen Gewinnung von ausreichend ungestörtem Probenmaterial für Laboranalysen wurden mit einer geschlossenen 1-m-Rammkernsonde mit Kunststoffinnenrohr ( $\varnothing 50 \mathrm{~mm}$ ) Rammkernsondierungen bis zu einer maximalen Tiefe von $8 \mathrm{~m}$ durchgeführt (u. a. Bohrkerne 1 und 2 bei Ober-Hörgern, Bohrkern 3 bei Oppershofen, Abb. 2-4). Dabei sind jeweils zwei Bohrungen, in der Tiefe um $50 \mathrm{~cm}$ versetzt, an jedem Standort niedergebracht worden, um durch Parallelisierung der 1-m-Bohrkerne eine lückenlose Abfolge der Schichten zu erhalten. Beim Aneinanderfügen der halbierten Kernsegmente im Labor ließ sich eine bohrtechnisch bedingte Komprimierung des Materials von ca. $10 \%$ feststellen. Neben botanischen Untersuchungen wurden an ausgewählten Standorten auch umfangreiche sedimentologische Analysen sowie Datierungen $\left({ }^{14} \mathrm{C}\right.$, OSL) durchgeführt (NolTE in Vorber.). Erste Sondagen erfolgten im Wettertal und Horloffgraben zuvor im Auftrag der Kommission für Archäologische Landesforschung in Hessen (FILzINGER 1992). Radiokarbondatierungen führten in Heidelberg (konv.) B. Kromer und in Utrecht (AMS) K. vaN DER BORG durch (Tab. 1).

Die drei Bohrkerne aus den Auenquerprofilen bei Ober-Hörgern (Bohrkern 1 und 2) und Oppershofen (Bohrkern 3) sind unter Berüicksichtigung lithologischer Gesichtspunkte für die botanischen Großrestanalysen in 141 Abschnitte bzw. Proben von 5 bis $10 \mathrm{~cm}$ Profillänge zerlegt worden. Weitere 4 Proben stammen aus einer Bohrung bei Gambach (Bohrpunkt 82) und aus Bohrung 6 des

Tab. 1: Übersicht der zu den botanisch untersuchten Sedimentproben gehörigen ${ }^{14} \mathrm{C}-\mathrm{Daten}$. Außer Sediment (organischer Substanz) wurden Samen und Früichte terrestrischer Arten datiert. Hd Heidelberg - konventionelle Datierung, UtC Utrecht - AMS, $\pm 1 \sigma$.

Table 1: ${ }^{14} \mathrm{C}$-dates from sediments used for botanical analyses. Dated were bulk samples of organic sediments or seeds and fruits from terrestrial species. Hd Heidelberg - conventional dating, UtC Utrecht - AMS, $\pm 1 \sigma$.

\begin{tabular}{|c|c|c|c|c|}
\hline Bohrkerntiefe (cm) & Labor-Nr. & Material & konv. BP & cal. BC \\
\hline \multicolumn{5}{|c|}{ Bohrkern 82 bei Gambach: } \\
\hline $317-322$ & |UtC-4901 & |Holz & $.2869 \pm 35$ & $\mid 1.110-945$ \\
\hline \multicolumn{5}{|c|}{ Bohrkern 1 bei Oberhörgern: } \\
\hline $129-134$ & Hd-18388 & Sediment & $3.360 \pm 47$ & $1.730-1.530$ \\
\hline $134-140$ & Hd-18389 & Sediment & $3.442 \pm 41$ & $1.854-1.683$ \\
\hline $277-293$ & UtC-5513 & Samen & $8.930 \pm 70$ & $8.030-7.940$ \\
\hline $327,5-330$ & UtC-4410 & Samen & $9.590 \pm 70$ & $8.970-8.530$ \\
\hline \multicolumn{5}{|c|}{ Bohrkern 2 bei Oberhörgern: } \\
\hline $175-180$ & UtC-5512 & Samen & $830 \pm 80$ & $\mathrm{AD} 1160-1280$ \\
\hline $264-274$ & UtC-5416 & Samen & $1.991 \pm 48$ & $36 \mathrm{BC}-\mathrm{AD} 75$ \\
\hline $285-298$ & Hd-18458 & Sediment & $7.715 \pm 66$ & $6590-6460$ \\
\hline $318-323$ & UtC-5415 & Samen & $7.890 \pm 60$ & $6.990-6.600$ \\
\hline $360,5-363$ & UtC-4403 & Samen & $9.160 \pm 70$ & $8.330-8.080$ \\
\hline $403-405,5$ & UtC-4404 & Samen & $9.470 \pm 70$ & $8.850-8.420$ \\
\hline \multicolumn{5}{|c|}{ Bohrung 6 bei Oberhörgern: } \\
\hline $177-193$ & |UtC-5514 & |Samen & $2.270 \pm 60$ & |390 - 200 \\
\hline \multicolumn{5}{|c|}{ Bohrkern 3 bei Oppershofen: } \\
\hline $275-280$ & UtC-5516 & Samen & $2.530 \pm 60$ & $800-530$ \\
\hline $350-357$ & UtC-4903 & Samen etc. & $2.270 \pm 35$ & $388-252$ \\
\hline $390-394$ & UtC-5515 & Samen & $2.866 \pm 32$ & $1.044-945$ \\
\hline
\end{tabular}




\section{$C^{14}$-Daten}

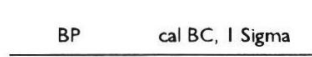

\begin{tabular}{|c|c|c|}
\hline & BP & cal BC, I Sigma \\
\hline (1) & $2270 \pm 60$ & $390-200$ (AMS) \\
\hline (2) & $5712 \pm 48$ & $4598-4469$ \\
\hline (3) & $6912 \pm 45$ & $577 \mid-5695$ \\
\hline (4) & $9389 \pm 48$ & $8488-8351$ \\
\hline (5) & $9810 \pm 53$ & $9050-9020$ \\
\hline (2) & $9815 \pm 67$ & $9050-9020$ \\
\hline (1) & $3360 \pm 47$ & $1730-1530$ \\
\hline (8) & $3442 \pm 41$ & $\mid 854-1683$ \\
\hline
\end{tabular}

$\begin{array}{cl}\text { BP } & \text { cal BC, I Sigma } \\ \text { (9) } 8930 \pm 70 & 8030-7940 \text { (AMS) } \\ \text { (1) } 9590 \pm 70 & 8970-8530 \text { (AMS) } \\ \text { (1) } 9570 \pm 50 & 8950-8530 \text { (AMS) } \\ \text { (1) } 3215 \pm 70 & 1520-1410 \\ \text { (1) } 7038 \pm 46 & 5952-5818 \\ \text { (1) } 8648 \pm 58 & 7840-7550 \\ \text { (1) } 10930 \pm 112 & 11020-10780 \\ \text { (1) } 11848 \pm 159 & 12080-11660\end{array}$

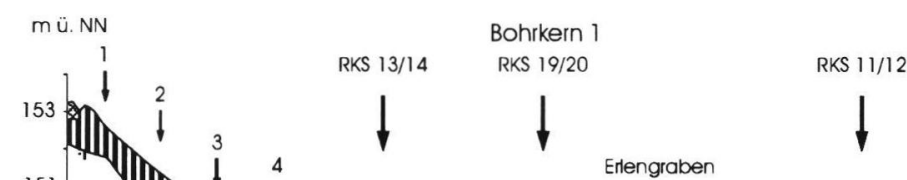

$11 / 12$

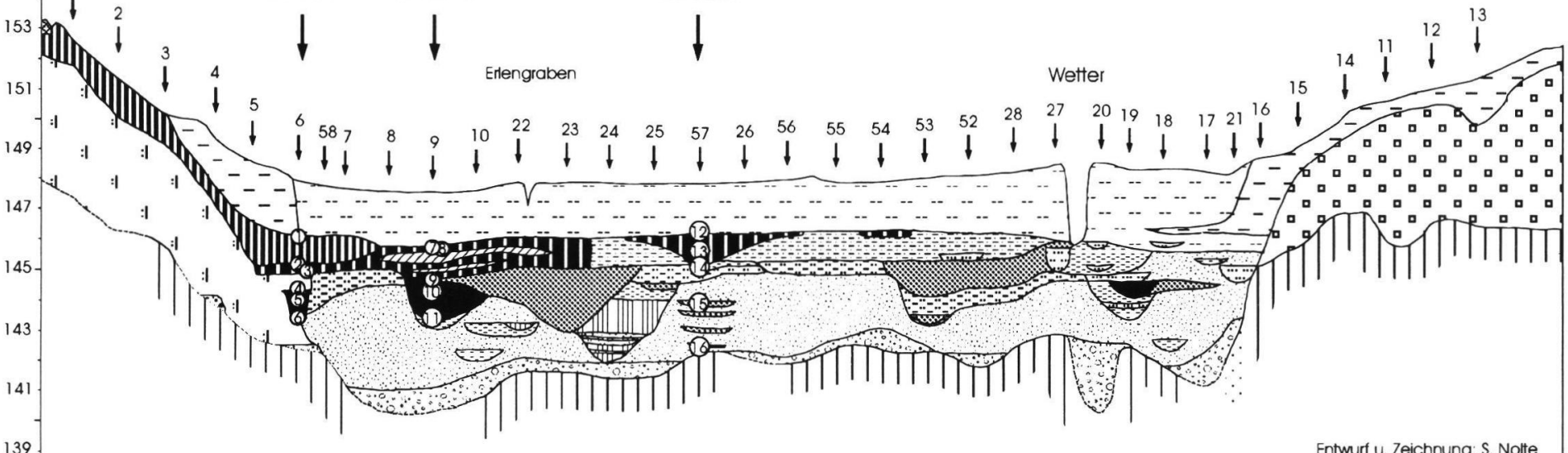

100

150

200

250

300

350

400

450

$500 \mathrm{~m}$

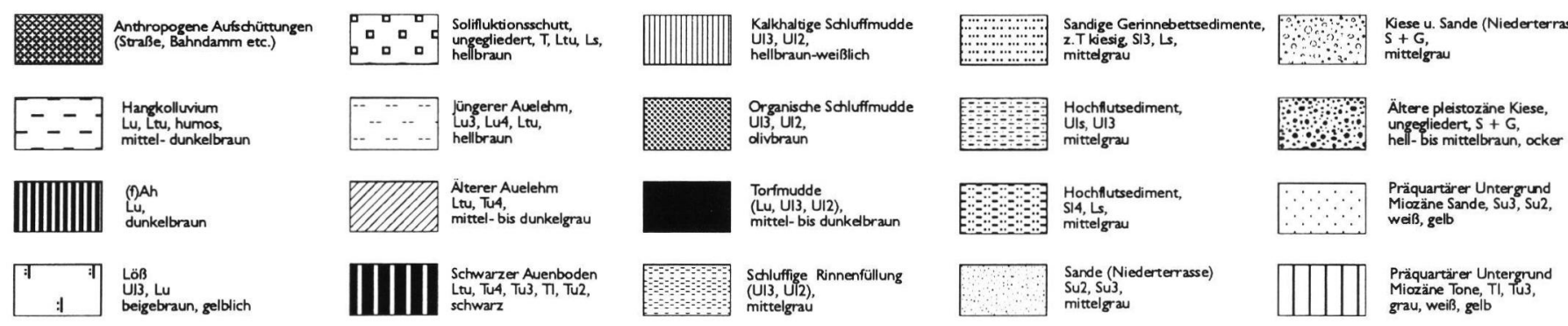

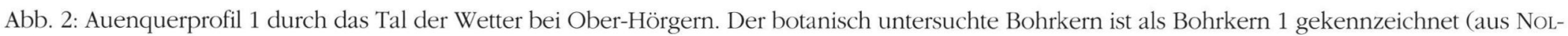
TE in Vorber.).

Fig. 2: Cross-section 1 in the Wetter valley near Ober-Hörgern. The core used for botanical analyses is marked Bohrkern 1 (from Nolte in prep.). 
$\begin{array}{cc} & \text { Bohrkern } 2 \\ \text { RKS } 15 / 16 & \text { RKS } 1 / 6\end{array}$

RKS $21 / 22$
mü. NN
$\downarrow$

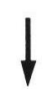
$\downarrow$

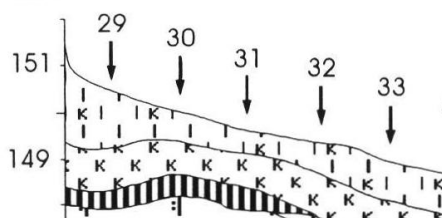

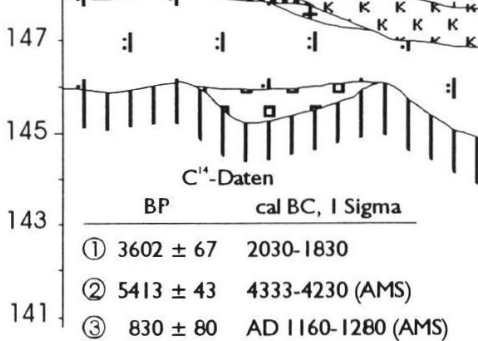

$0 \quad 50 \div 100$

$: 1 \frac{1}{1}: \frac{k}{1}$

सरी

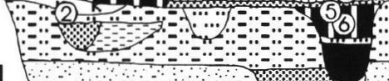

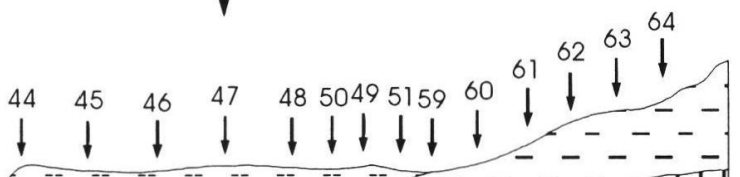
$\begin{array}{ccccc}39 & 40 & 41 & 42 & 43\end{array}$

1

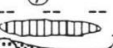

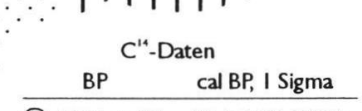

1 pit

:|

(4) $1991 \pm 48 \quad 36-\mathrm{AD} 75$ (AMS)

(5) $7715 \pm 66 \quad 6590-6460$

(6) $7890 \pm 60 \quad 6990-6600$ (AMS)

(7) $2040 \pm 60 \quad 100-A D 50$ (AMS)

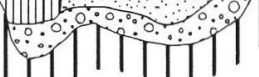

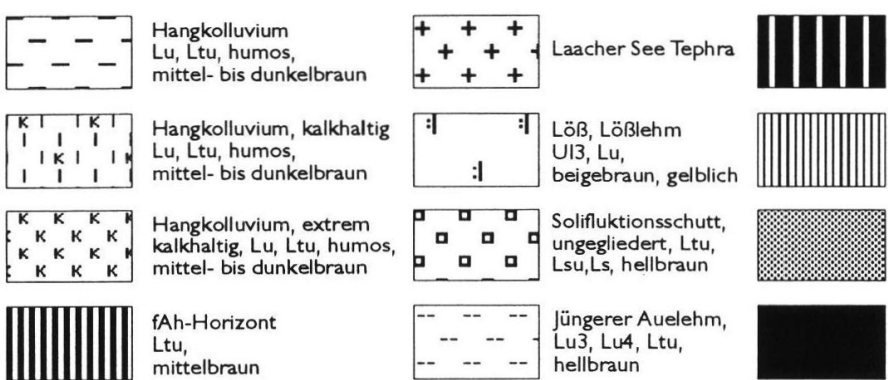

200

250

300

350

Schwarzer Auenboden
Ltu, Tu4, Tu3, TI, Tu2,

schwarz

alkhaltige Schluffmudde, UI3, UI2,

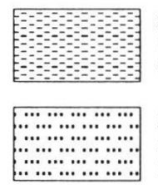

Schluffige Rinnenfüllungen, Ul3 olivgrau Organische Schluff-
mudde, U13, U12 olivbraun

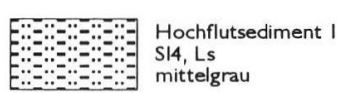

Torfmudde,

(Lu, UI3, UI2),

mittel- bis dunkelbraun
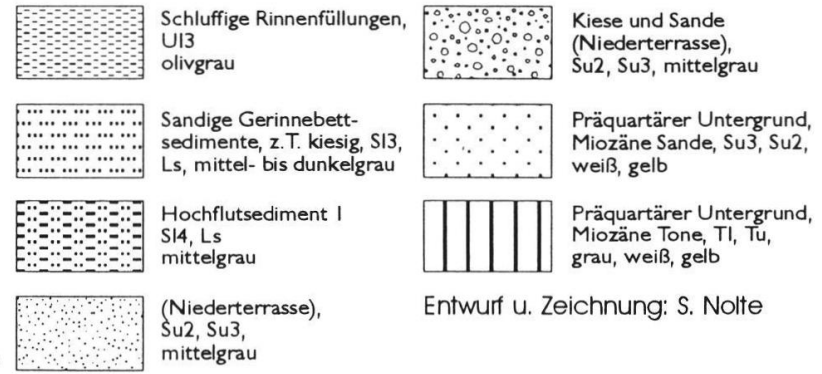

, TI, Tu, Miozäne Tone, TI,
grau, weiß, gelb

Entwurf u. Zeichnung: S. Nolte

Abb. 3: Auenquerprofil 2 durch das Tal der Wetter bei Ober-Hörgern. Der botanisch untersuchte Bohrkern ist als Bohrkern 2 gekennzeichnet. Weitere Großrestproben stammen aus Bohrung 6 (aus NOLTE in Vorber.).

Fig. 3: Cross-section 2 in the Wetter valley near Ober-Hörgern. The core used for botanical analyses is marked Bohrkern 2, see also core 6 (from NolTE in prep.). 


\begin{tabular}{|c|c|c|c|c|c|c|}
\hline & & & & Dater & & \\
\hline & & BP & Cal BC, I Signa & & BP & Cal BC, I Signa \\
\hline & & (1) $1238 \pm 47$ & $A D 714-881$ & (8) & $2530 \pm 60$ & 800.530 \\
\hline & & (2) $1804=40$ & $A D$ 148-318 & (2) & $2270 \pm 35$ & 388.252 \\
\hline & & (3) $5814 \pm 61$ & $4770-4580$ & (1) & $2866 \pm 32$ & $1044-945$ \\
\hline rkem 3 & & (4) $5570 \pm 81$ & $1470-4340$ & (11) & $9330 \pm 500$ & $9050-7920$ \\
\hline $10 / 27$ & & (5) $11306 \pm 77$ & $\mid 1370-11170$ & (12) & $11908 \pm 69$ & $12070-1 \mid 1800$ \\
\hline $5 / 26$ & IXSS 23/24 & (3) $12261 \pm 61$ & $12530-12220$ & (13) & $12724 \pm 124$ & $13290-12790$ \\
\hline & & (8) $13002 \pm 77$ & $13650-13310$ & (14) & $17861 \pm 350$ & $19830-18860$ \\
\hline
\end{tabular}
Bohrkem 3 RKS 10/2

$\downarrow \downarrow$

147.

$143+-\ldots+121$

- $=-\ldots+1+111817$

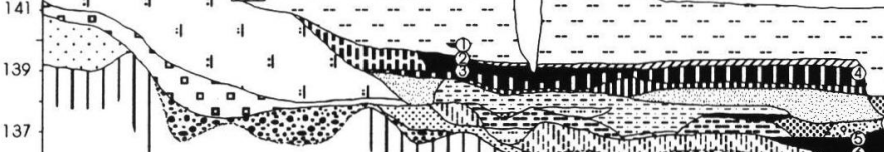

135

133. (3)

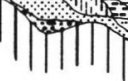

$\prod \because \because$

0

50

100

150

200

250

300

350

400

450

500

Entwurf u. Zechnung S. Nate

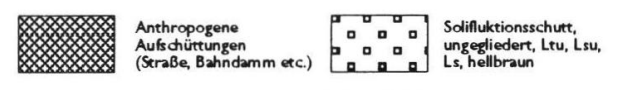

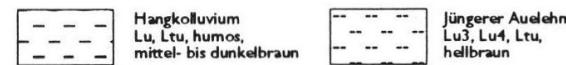

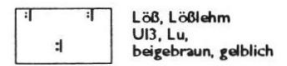

VIIII Ätrerer Audehm

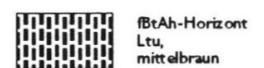

\|\|\|\| $\begin{aligned} & \text { schwarzer Auenboden } \\ & \text { Ltu, Tu4, Tu3, T1, Tu2, } \\ & \text { schwarz }\end{aligned}$

Organische Schluffmudde
OII. U12
olivbraun

Hochlutsediment 3

Untere Niederterrasse
Su2,Su3
mittel- bis dunkelgrau

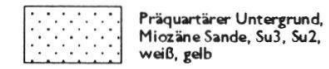

(2)

orfmudde. Hochnutsediment 2

(Lu, U13, Ui2),
mittel- bis dunkelbra

Hochnutsedimeme 2
Lu Ltu
hell-bis mittelgrau

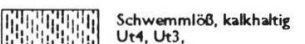

गागा Präquartärer Untergrund,

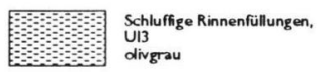

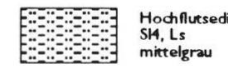

Altere Plesstozäne Kiese
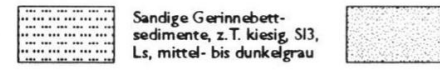

Sande der Oberen
Niederterrasse, Su2,
Su3, mittelgrau

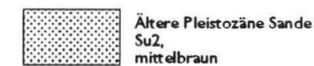

[3:3
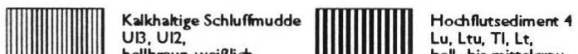

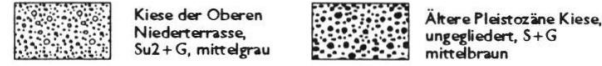

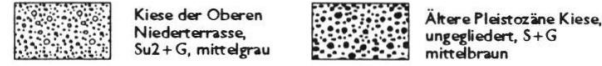

Pitrel-bis hellbraun

U13, UI2,
hellibraun-weiblich

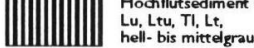

TE in Vorber.).

Fig. 4: Cross-section 3 in the Wetter valley near Oppershofen. The core used for botanical analyses is marked Bohrkern 3 (from NoLTE in prep.). 
Auenquerprofils Ober-Hörgern. Ergänzend wurden aus Bohrkern 2 zwischen 1,78 und 2,84 m Tiefe 13 Proben pollenanalytisch untersucht. Die tieferen Abschnitte der Profile bearbeitet H. Bos, Utrecht, im Rahmen ihrer Dissertation.

Eine teilweise Ausräumung und erneute Sedimentierung des Wettertales erfolgte in der WürmEiszeit. In den Profilen ließen sich vereinzelt spätglaziale und präboreale, torfige Rinnenfüllungen, eingeschnitten in spätglaziale, sandige Hochflutsedimente, nachweisen (Abb. 2-4 sowie NolTE in Vorber.; Chronozonen nach MANGERUD ET al. 1974, 1982). Im Präboreal lag der Boden des Wettertales ca. 3-4 Meter tiefer als heute. Der bereits in mehreren Arbeiten beschriebene, sogenannte Schwarze Auenboden (u. a. Mä́KEL 1969; SABEL 1982) ließ sich auch in den drei hier behandelten Profilen nachweisen (Abb. 2-4). Er wurde nach derzeitigem Forschungsstand in einem Zeitraum von mehreren Jahrtausenden in den Chronozonen Boreal/Atlantikum gebildet. Infolge des Fehlens oder der extrem schlechten Erhaltung botanischer Reste in diesem Horizont, könnte er als terrestrische Bildung interpretiert werden oder die Folge späterer Grundwasserabsenkung sein.

Über diesem Horizont folgen 2-3 Meter homogene jüngere Auenlehme (schluffige und schluffigtonige Lehme), die hauptsächlich in den letzten 2000 Jahren abgelagert wurden. Ursachen und Einsetzen der Auenlehm-Akkumulation in Flußtälern wurden vielfach und kontrovers diskutiert (vgl. JÄGER 1962; HuCKriede 1971; SCHIRMER 1983; Hiller et al. 1991: 37ff.; CASpers 1993; JOCKENHÖVEL 1994: 78ff.; URZ 1995). Der derzeitige Forschungsstand läßt regionale Unterschiede deutlich werden, die aus verschiedenen geomorphologischen und klimatischen Gegebenheiten, wie auch anthropogenen Aktivitäten resultieren. Eine zeitliche Auenlehmdifferenzierung (z. B. HiLler et al. 1991: 39) war im Wettertal erschwert, da in den Bohrkernen keine begrabenen Bodenhorizonte erkennbar sind (NoLTE in Vorber.). Datierbares organisches Material fehlt leider in den oberen 1-2 Metern des Auenlehms. Die Auenlehmdifferenzierung in Auenquerprofil 3 wurde aufgrund von unterschiedlichen Korngrößen vorgenommen, bei Auenquerprofil 1 erfolgte eine Trennung von Schwarzem Auenboden und Auenlehm aufgrund unterschiedlicher Organikgehalte der Sedimente (Abb. 2 und 4).

Die erfaßten Sedimenteinheiten in den drei Auenquerprofilen zeigen, daß sich die Standortbedingungen in der Aue im Spätglazial und Holozän erheblich verändert haben.

\section{Ergebnisse der botanischen Großrestanalysen}

(A. Kreuz)

\subsection{Zur Methode}

Vegetationsgeschichtliche Arbeiten konzentrieren sich gewöhnlich auf die Waldgeschichte zonaler Vegetationsgruppen. Die Entwicklung der Täler mit ihren azonalen und anderen Pflanzengesellschaften ist bisher weniger differenziert erforscht (Ausnahmen z. B.: Willerding 1962; GrosSe-Brauckmann et al. 1990; NeEdHam \& Macklin 1992; Caspers 1993; Arora et al. 1995; Urz 1995; KNÖRZER 1996). Insbesondere mangelt es an Untersuchungen kleinerer Fluß- und Bachtäler. Dies ist insofern bedauerlich, als die Fluß- und Bachtäler der Altsiedellandschaften in der gesamten Vor- und Frühgeschichte wichtige Nutzungsräume für Viehzucht, Jagd, Fischfang, Transport, Handwerk und als Rohstoffquellen darstellten.

Jeder Bach oder Fluß führt unter anderem durch Erosion und vom Wind eingetragene organische Stoffe mit sich, die in flachen Uferbereichen abgelagert werden. Solches „Gespülnis" kann nur dann erhalten bleiben, wenn es möglichst rasch von luftundurchlässigem Sediment überdeckt wird oder in den Grundwasser-Einflußbereich gerät. Dies ist bei den hier untersuchten Bohrkernen offenbar nur ausnahmsweise der Fall gewesen, da lediglich bei einem Drittel aller untersuchten Proben eine gute Pflanzenerhaltung vorlag.

Eine bessere Möglichkeit der subfossilen Erhaltung von Pflanzenresten in Flußtälern besteht im Bereich von verlandenden Altarmen (oxbow lakés) oder von Niedermooren der Randsenken eines Flußtales. Dort trägt vor allem die lokale Vegetation (pflanzliche Großreste, Pollenkörner und Sporen), aber auch die der näheren oder weiteren Umgebung (vor allem Pollenkörner und Sporen) zur Ablagerung bei. Bei den hier behandelten Bohrkernen war eine gute Erhaltung pflanzlicher Großreste außer in Rinnensedimenten (Torfmudden oder organische Schluffmudden von Altarmen) zum Teil auch in Auenlehmen gegeben. Ergänzend zu den systematisch geborgenen Proben aus den drei Bohrkernen wurde noch Material aus zwei Bohrungen bei Gambach (82) und Ober-Hörgern (6) analysiert (vgl. Kap. 2 und Tab. 2).

Die 145 Proben für die Großrestuntersuchungen wurden in Wasser gelöst und die organischen Bestandteile auf einem Sieb mit 0,25 mm Maschenweite gesammelt. Bessere Löslichkeit der Sedimente konnte durch mehrtägiges Tieffrieren der 
Proben erzielt werden. Die Schlämmrückstände wurden unter einer Stereolupe (Binokular) bei 6bis 12-facher Vergrößerung durchgesehen und alle bestimmbaren pflanzlichen Reste aussortiert. Die Mittel für die technische Aufbereitung der Proben erhielten wir dankenswerterweise größtenteils von der Deutschen Forschungsgemeinschaft (DFG).

Insgesamt konnten mit Großresten 109 Taxa nachgewiesen werden, darunter 89, die sich paläoökologisch interpretieren lassen (Tab. 2 und 3). Hinzu kommen seltenere Funde von Fischresten (Wirbel, Schuppen), Mollusken (vor allem Operculi) und Kleinsäugern sowie regelmäßig von Insekten (Tab. 2), die hier keine Berücksichtigung finden können.

Die Proben in den oberen Abschnitten waren weitgehend fundleer: Bohrkern 1 bis $2,68 \mathrm{~m}$ Tiefe, Bohrkern 2 bis 1,60 m Tiefe, Bohrkern 3 bis $2,50 \mathrm{~m}$ Tiefe. Im folgenden werden nur die Proben mit Großresterhaltung behandelt (Tab. 2 u. 3). Die bessere Konservierung der Pflanzenreste (auch Pollen/Sporen) in Bohrkern 2 dürfte sich aus der Nähe des Flußbettes erklären. Die Wetter fließt heute in ca. $10 \mathrm{~m}$ Entfernung von Bohrung 2, hingegen ca. $220 \mathrm{~m}$ von Bohrung 1 und $120 \mathrm{~m}$ von Bohrung 3 entfernt (Abb. 2-4).

Es fällt auf, daß nicht nur in den oberen Abschnitten, sondern auch in den tieferen Bereichen mit Pflanzenerhaltung beispielsweise die subfossilen Hölzer oft sehr schlecht konserviert sind und zarte Samen oder Früchte (z. B. Grasfrüchte, Gramineae) weitgehend fehlen. Die Hölzer sind häufig stark abgebaut, was darauf schließen läßt, daß sie vor ihrer primären oder späteren (Umlagerung?) Einbettung bereits längere Zeit unter Sauerstoffeinfluß ensprechenden Organismen ausgesetzt waren. Mit einer "Zersetzungsauslese“ aufgrund wechselnder hydrologischer Bedingungen, wie von Firbas (1949: 29) als methodisches Problem der Pollenanalyse beschrieben, muß hier auch für die pflanzlichen Großreste gerechnet werden. Eine quantitative Auswertung ist nicht nur aus diesem Grund schwierig. Es kommt hinzu, daß in den drei Bohrkernen unterschiedliche, teils durch Hiaten getrennte Zeitabschnitte in unterschiedlicher Mächtigkeit vertreten sind, was eine vergleichende Interpretation erschwert. Hier wird allerdings die künftige Untersuchung von Proben aus weiteren Bohrungen des Wettertales weiterhelfen.

Im folgenden sollen die in den fünf Bohrkernen bzw. Profilen an Hand der Großreste nachgewiesenen Vegetationsgruppen im einzelnen vorge- stellt werden (vgl. Tab. 2 u. 3). Die Gruppierung der gefundenen Taxa erfolgte nach ElLENBERG (1979) und Oberdorfer (1990). Eine Eingruppierung war nicht immer einfach, da die heutigen syntaxonomischen Einheiten nicht für das Frühholozän (Präboreal/Boreal) oder das frühe Atlantikum gelten (Chronozonen nach MANGERUD et al. 1974, 1982; zu den ${ }^{14} \mathrm{C}$-Daten vgl. Tab. 1). Wenn heute mehrere Standorte in Frage kommen, wurde ein auennaher gewählt. Dies betrifft insbesondere die Gruppen heutiger Unkraut- und Ruderalpflanzen, die teils Apophyten darstellen, also Arten, die ihre Wuchsorte von der natürlichen, meist azonalen Vegetation der Flußtäler auf anthropogene Standorte ausgedehnt haben (Kreuz 1993a, dort weitere Literaturangaben).

\subsection{Süßwasser- und Moorvegetation stehen- der oder langsam fließender Gewässer}

Laichkraut- und Schwimmblattgesellschaften

Es fanden sich Großreste von 3-5 Taxa verwurzelter Wasserpflanzengesellschaften (heute Potamogetonetea), die Röhrichtgürteln vorgelagert sind (Tab. 2). Laichkraut (Potamogetum sp.) und Wasser-Hahnenfur (Ranunculus sp. sect. Batrachium) konnten nicht weiter differenziert werden.

\section{Röhrichte und Seggenriede}

Neun Arten der Verlandungsgesellschaften (heute Phragmitetea) nährstoffhaltiger Gewässer traten auf (Tab. 2). Das Fehlen von Schilfrohr-Früchten, Phragmites australis, kann nicht dahingehend interpretiert werden, daß Schilf an den drei Lokalitäten im Wettertal tatsächlich nicht vorkam. Wahrscheinlicher ist, daß die natürlicherweise nur selten gut (reif) ausgebildeten SchilfrohrFrüchte - wie auch die anderer Süßgräser - infolge Erhaltungsselektion in den Proben fehlen.

\section{Kleinseggenrieder}

Hinweise auf eine Kleinseggenvegetation (heute Scheuchzerio-Caricetea nigrae), wie man sie auf Flach- oder Quellmooren und Verlandungssümpfen (Sumpfrasen) findet, geben die vereinzelten Funde von vier Arten (Tab. 2). Hier wuchs möglicherweise auch der Gewöhnliche Gelbweiderich (Lysimachia vulgaris, vel nummularia/nemorum).

Die Samen und Früchte von insgesamt 20 Arten entstammen der Vegetation stehender (Altarme) oder langsam fließender, eher nährstoffreicher, von Röhricht und Seggenrieden umgebener Gewässer. Die betreffenden Arten fanden sich in al- 
len Zeitabschnitten der untersuchten Bohrkerne (Tab. 2 u. 3), so daß ein kontinuierlicher Bestand an Süßwasser- und Moorvegetation rekonstruiert werden kann.

\subsection{Krautige Vegetation oft gestörter Plätze}

Die nächste Großgruppe läßt sich gliedern in natürlich verbreitete, azonale Arten sowie Arten ungewisser Verbreitung. Letztere (Kap. 3.6 u. 3.7) sind für die Frage der anthropogenen Beeinflussung des Auenstandortes von Bedeutung. Zunächst zu den wahrscheinlich natürlich verbreiteten Taxa:

\section{$\underline{\text { Schlammufergesellschaften }}$}

Hierzu gehören kurzlebige Pflanzengemeinschaften, die sich bei günstigen Bedingungen des Substrates (zum Beispiel fehlender Überstauung durch Wasser) und entsprechend vorteilhaften klimatischen Verhältnissen kurzfristig entwickeln (heute Bidentetea), zum Beispiel im Gleithangbereich eines Flußmäanders. Samen oder Früchte von 5 Arten dieser Gruppe konnten in Bohrkern 2 und 3 erfaßt werden (Tab. 2).

Das Fehlen solcher Taxa im Bohrkern 1 und den Proben der Bohrung bei Gambach kann vielfältig bedingt sein und ist nicht interpretierbar. Die Arten gelten nach KORNECK \& SuKOPP (1988) nicht als kulturabhängig. Ihre natürliche Verbreitung im Wettertal ist somit möglich, schließlich tritt der
Ampfer-Knöterich, Polygonum lapatbifolium, auch bereits in frühatlantischen Proben auf.

Unkraut- und Ruderalgesellschaften

Hier wurden sechzehn Taxa zusammengefaßt, die auf nährstoffreichen Böden unterschiedliche Unkrautfluren bilden, und die heute vor allem zu den drei durch die Einwirkung von Menschen und Tieren geprägten Gruppen Chenopodietea (Ruderalgesellschaften u. verwandte Acker- u. Garten-Beikrautgesellschaften), Artemisietea vulgaris (Ausdauernde Stickstoff-Krautfluren) und Plantaginetea (Tritt- u. Feuchtpionierrasen) gezählt werden (Tab. 2).

Es handelt sich allerdings um Arten, die auch in stickstoffliebenden Staudenfluren der Bachufer und von anderen (Süß-)Gewässern sowie in Auwäldern wachsen, weshalb ihr natürliches Vorkommen im Wettertal durchaus denkbar ist. Hierfür spricht gleichfalls, daß es sich bei 10 Taxa um Pionierpflanzen handelt (Tab. 2). Auf den im Sommer weitgehend trockenen Uferbereichen boten sich optimale Nährstoff- und Lichtbedingungen.

In den drei Profilen fanden sich von den betreffenden sechzehn Arten nur Zottiges Weidenröschen (Epilobium cf. hirsutum), Wasserdost (Eupatorium cannabinum), Wassermiere (Myosoton aquaticum), Kriechender Hahnenfuß (Ranunculus repens) und Große Brennessel (Urtica dioica)

Tab. 2: Pflanzliche Großreste aus holozänen Sedimentproben des Wettertales (Hessen): Bohrkerne 1 und 2 bei Ober-Hörgern (Ohö4, 9 (19 u. 20) sowie Ohö5, 43 (1 u. 6)), Bohrkern 3 bei Oppershofen (Opp1, 107 (10 u. 27)). Legende: Probennummern datierter Proben kursiv; Hoch-MA Hoch-Mittelalter, Sp.o. Fr. Subatl. Spätes o. Frühes Subatlantikum, EZ/RKZ Übergang späte Eisenzeit/frühe Römische Kaiserzeit, HA wahrscheinlich Hallstatt-Zeit, Sp. Subbo Spätes Subboreal, Spät-BZ Spät-Bronzezeit; Bor./Atl. Boreal/Atlantikum; ${ }^{*}$ Pionierpflanze, ${ }^{* *}$ Kriechpionierpflanze; Zahlen $=$ Anzahl Nachweise (Erläuterungen im Text (Kap. 3); vgl. auch Tab. 3). Fettgedruckte Taxa sind im Bohrkern 2 auch pollenanalytisch nachgewiesen (vgl. Kap. 4 u. 5). Aus zwei weiteren Bohrungen (Auelehme) bei Gambach (82; Spätes Subboreal/Spät-Bronzezeit) und Ober-Hörgern (6; Frühes Subatlantikum/Latène) wurden 4 Proben untersucht.

Gambach 82: 1 Nuphar lutea, 1 Mentha aquatica (/arvensis), 2 Typhasp., 1 Potamogetonsp., 1 Ranunculussp. Sect. Batrachium, 1 Chenopodium cf. ficifolium, 1 Potentilla anserina, 2 Ranunculus repens, 12 Urtica dioica, 8 Filipendula ulmaria, 1 Lychnis flos-cuculi, 1 Valeriana cf. dioica, 1 Hypericum perforatum, 15 Alnus glutinosa Fr. (+ 1 Holz), 1 Quercus sp. Holz, 2 Solanum dulcamara, 1 Arenaria serpyllifolia, 1 Stellaria graminea, 2+1cf. Solanum nigrum, 3 Carex sp., 1 Juncus sp., 3 Sambucus sp., HK. Ober-Hörgern 6: 1 Fischwirbel, 1 Conium maculatum, 1 Sambucus ebulus, 2 Urtica dioica, 5 Quercus sp. Holzkohle, 1 Stachys cf. sylvatica (Jannua), 1 Plantago lanceolata (verk.), 1 Trifolium campestre usw., 1 Hyoccyamus niger, 1 Hordeum sp., 2 Cerealia indet., 1 Hüllspelzenbasis Triticum dicoccum/spelta, 5 Atriplex/Chenopodium, 2 Carexsp., 11 Sambucus sp., HK, Insekten.

Table 2: Botanical macro remains from Holocene sediments from the Wetter valley (Hessen): cores 1 and 2 near Ober-Hörgern (Ohö4, 9 (19 and 20) and Ohö5, 43 (1 and 6), core 3 near Oppershofen (Opp1, 107 (10 and 27). Legend: sample numbers of dated samples in italics; Hoch-MA High Middle Ages, Sp. o. Fr. Subatl. Late or Early Subatlantic, EZ/RKZ transition Late Iron Age/Early Roman Period, $H A$ probably Hallstatt period, $S p$. Subbo Late Subboreal, Spät-BZ Late Bronze Age, Bor./Atl. Boreal/Atlantic; * pioneer plant, ${ }^{* *}$ creeping pioneer plant; numbers $=$ number of identifications (explanations in the text (chapter 3), also see Table 3). Taxa in bold letters were also identified by pollen in cross-section 2 (see chapters 4 and 5). Further 4 samples come from core 82 near Gambach and from core 6 near Ober-Hörgern (list of plant taxa see above). 


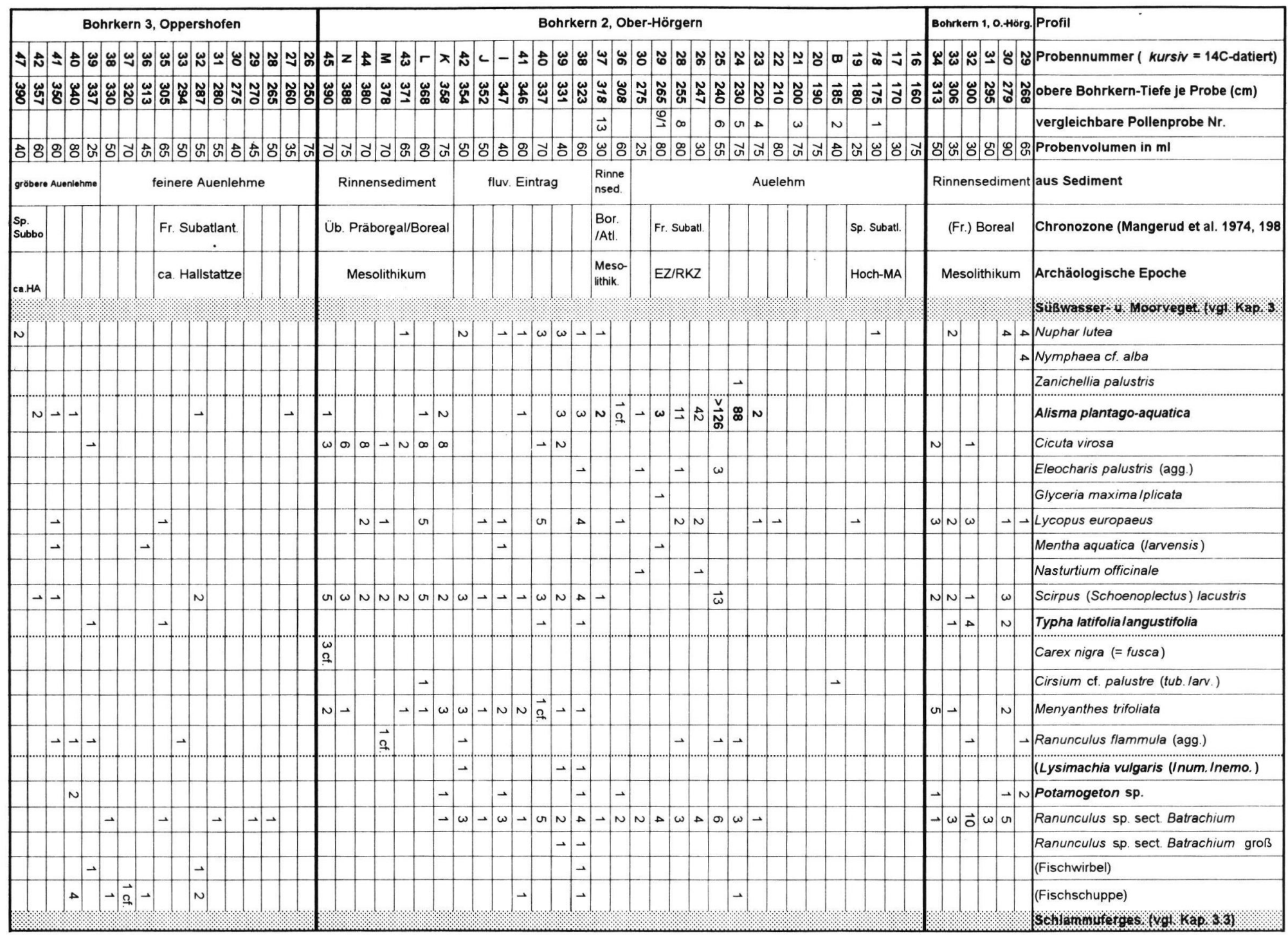




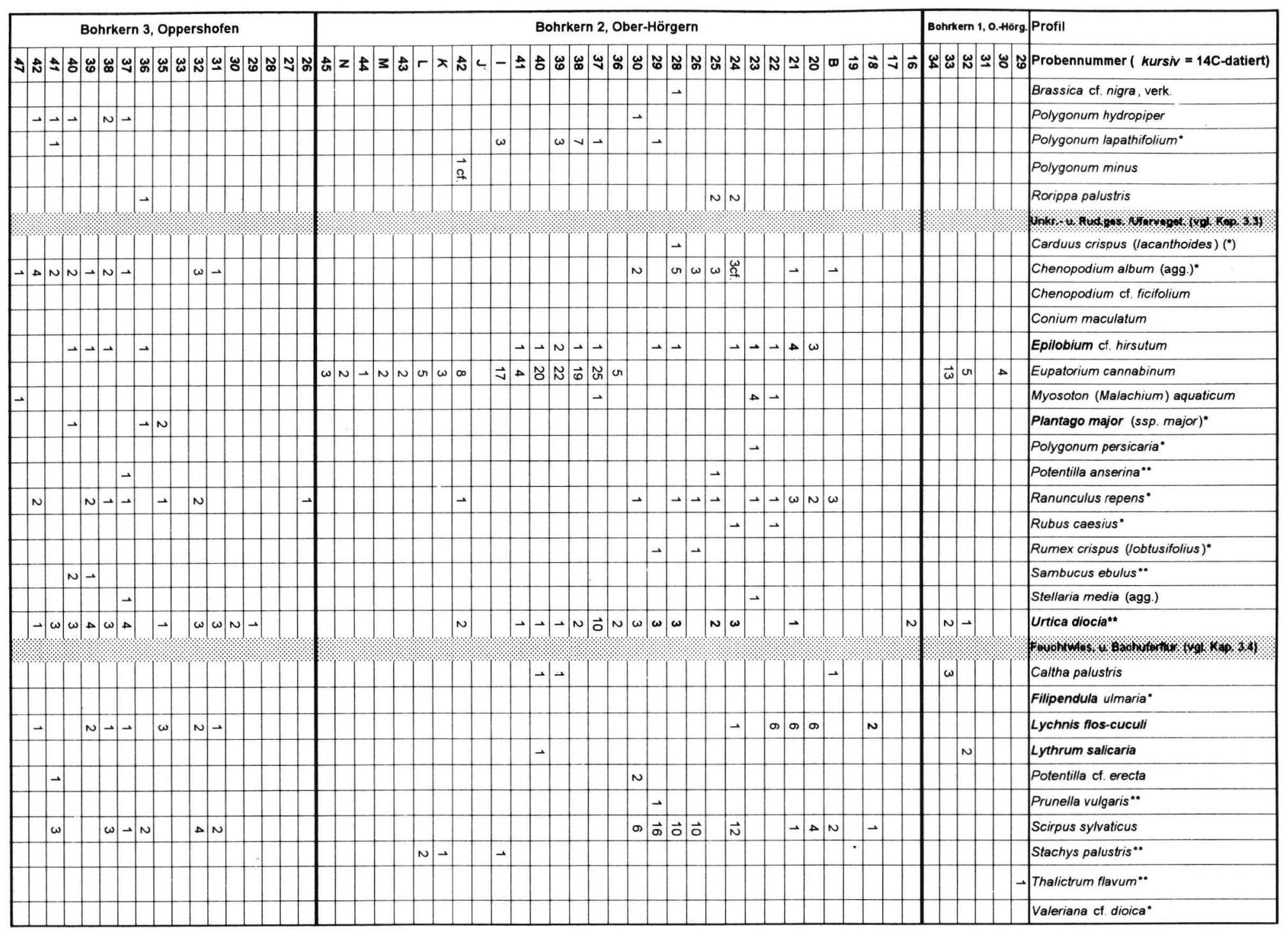




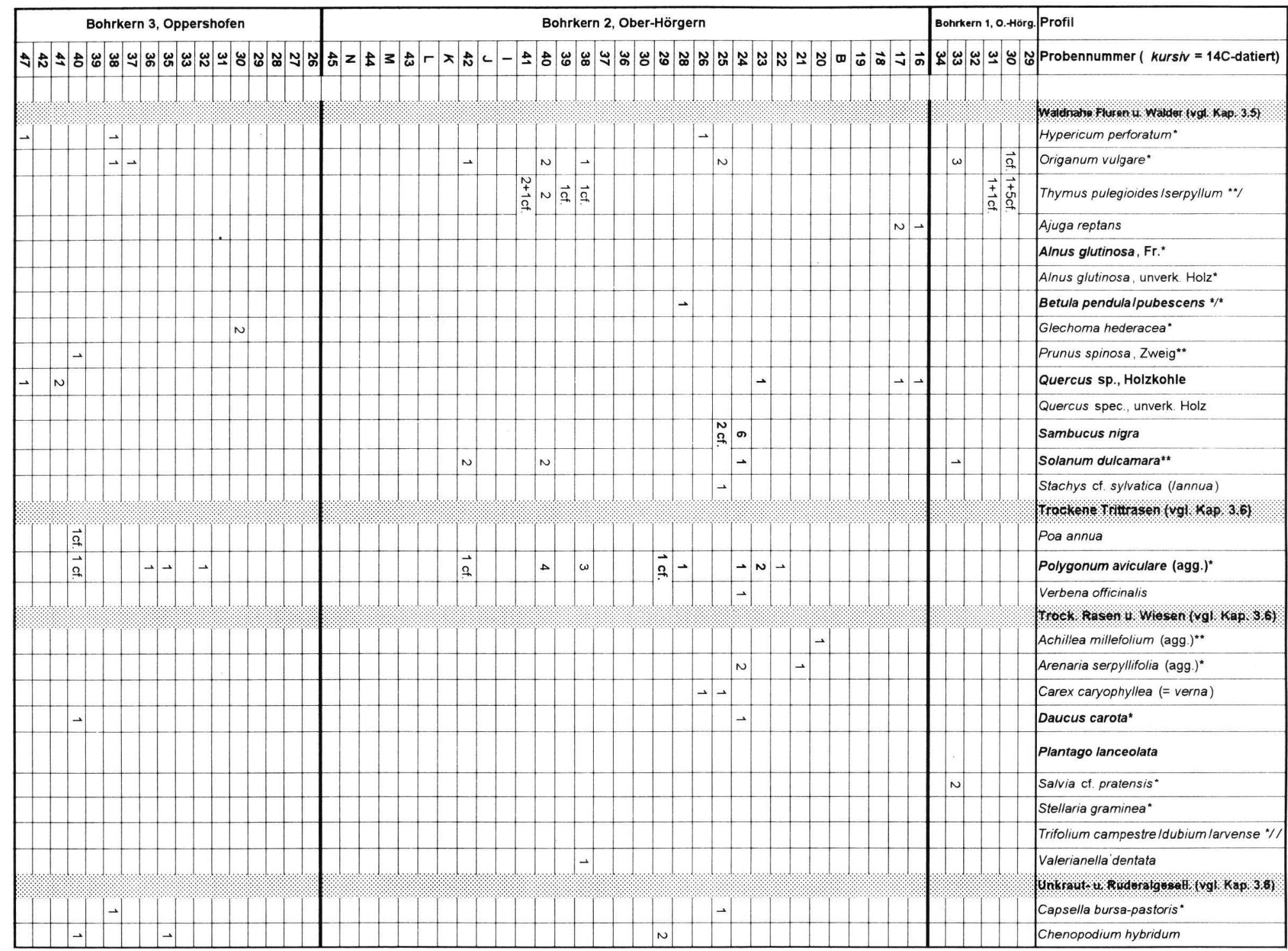




\begin{tabular}{|c|c|c|c|c|c|c|c|c|c|c|c|c|c|c|c|c|c|c|c|c|c|c|c|c|c|c|c|c|c|c|c|c|c|c|c|c|c|c|c|c|c|c|c|c|}
\hline & & & & hrrk & kern & 3, & Opr & oper & rshof & & & & & & & & & & & & & & & Bohrk & kern & 2,0 & Ober & r-Hör & irger & & & & & & & & & & & & thrker & m 1, & 0.Hör & rg. Profil \\
\hline 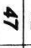 & जि! & 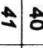 & $\boldsymbol{\omega}$ & $\boldsymbol{\Phi}_{\infty}$ & $\boldsymbol{\omega}$ & $\boldsymbol{\omega}$ & w్ & $\boldsymbol{\omega}$ & $\underset{\mathcal{N}}{\omega} \stackrel{\omega}{ }$ & $\boldsymbol{\omega}$ & $\tilde{\omega}$ & $\mathbb{\infty} \sim$ & ง స & जे & $\mathbf{z}$ & $\mathbf{t}$ & $3 \vec{\omega}$ & $r$ & $x$ & $\vec{N}$ & $c$ & - \pm & $=$ of & $\boldsymbol{\omega}$ & $\boldsymbol{\omega}$ & $\underset{v}{\omega}$ & $\omega$ & $\tilde{0}$ & ๗ & ก & 今 & $\approx$ & $\tilde{\omega}$ & 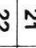 & O & $\boldsymbol{\infty}$ & $\vec{\omega} \vec{\alpha}$ & $\vec{\infty} \vec{v}$ & $\vec{\sigma}$ & & $\omega$ & $\stackrel{\omega}{\omega} \omega$ & $\tilde{\omega}$ & (s) Probennummer ( kursiv $=14 \mathrm{C}$-datiert) \\
\hline & & & & & & & & & & & & & & & & & & & & & & & & & & & & & & & & & & & & & & & & & & & & \\
\hline & & & & & & & & & & & & & & & & & & & & & & & & & & & & & & & & - & $\rightarrow$ & & & & & & & & & & & Euphorbia helioscopia \\
\hline & & N & & & & & & & & & & & & & & & & & & & & & & & & & & & & & & & & & & & & & & & & & & Fumaria officinalis \\
\hline & & & & & & & & & & & & & & & & & & & & & & & & & & & & & N & & $\rightarrow$ & & & & & & & & & & & & & Hyoscyamus niger \\
\hline & & & & & & & & & & & & & & & & & & & & & & & & & & & & $\rightarrow$ & & & & & & & & & & & & & & & & Lamium amplexicaule/purpureum \\
\hline & & & & & & & & & & & & & & & & & & & & & & & & & & & & & & & & $\rightarrow$ & & & & & & & & & & & & Lapsana communis* \\
\hline & $\rightarrow$ & & & & & & & & & & & & & & & & & & & & & & & & & $\rightarrow$ & & & & & & $\rightarrow$ & & & & & & & & & & $\rightarrow$ & & Solanum nigrum \\
\hline & & & & & & $\vec{a}$ & & & & & & & & & & & & & & & & & & & & & & & & & & & & & & & & & & & & & & Thlaspi anvense \\
\hline & & & & & & & & & & & & & & & & & & & & & & & & & & & & & & & & & & & & & & & & & & & & 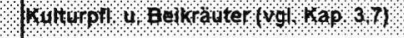 \\
\hline & & & & & & & & & & & & & & & & & & & & & & & & & & & & & & & N & & & & & & & & & & & & & Polygonum convolvulus \\
\hline & & $\vec{a}$ & & & & & & & & & & & & & & & & & & & & & & & & & & & & & & & & & & & & & & & & & & Hordeum sp., verk. Korn (cult.) \\
\hline & & & & & & & & & & & & & & & & & & & & & & & & & & & & $\rightarrow$ & & & & & & & & & & & & & & & & Triticum sp., verk. Korn \\
\hline & & & & & & & & & & & & & & & & & & & & & & & & & & & & & & & & & & & & & & & & & & & & Cerealia indet., verk. \\
\hline & & & & & & $\rightarrow$ & & & & & & & & & & & & & & & & & & & & & & & & & & & & & & & & & & & & & & Papaver somniferum \\
\hline & & & & & & & & & & & & & & & & & & & & & & & & & & & & & & & & & & & & & & & & & & & & Triticum dicoccum/spelta HSB, verk. \\
\hline & & & & & & & & & & & & & & & & & & & & & & & & & & & & & & & & & & & & & & & & & & & & sonstiges \\
\hline & & $\rightarrow$ & $\rightarrow$ & & & & & & $\rightarrow$ & & & $\rightarrow$ & & & & & & & & & & & & & & & & $N$ & & & $\rightarrow$ & & - & $\rightarrow$ & & & & & & & & & & Atriplex/Chenopodium sp. \\
\hline & & & & & & & & & & & & & & & & & & & & & & & & & & & & & $\rightarrow$ & & & & & & & & & & & & & & & Carduus sp. (crispus /acanthoides?) \\
\hline$\rightarrow$ & $n$ & $\omega$ & $\omega \rightarrow$ & & $\rightarrow$ & & N & & $\rightarrow$ & & & & & $\Delta$ & $\omega=$ & $\vec{\Delta}$ & on 0 & $\overrightarrow{0}$ & $\exists$ & N & $\infty$ & $\stackrel{\omega}{\omega} \tilde{c}$ & 2 & $\vec{\omega}$ & $\tilde{\omega} \mid \bar{n}$ & $\vec{N}$ & & $\rightarrow$ & $\omega$ & $N$ & -5 & $\vec{\omega} \wedge$ & N & a & & & & & & & $V N$ & N & $\vec{A}$ & $\triangle$ Carex sp./Cyperaceae \\
\hline & & $\overrightarrow{9}$ & $\vec{?}$ & & & & & & $\rightarrow$ & & & & & & & & & & & & & & & & & & & & & & & N- & $\rightarrow$ & & & & & & & & & & & Caryophyllaceae ICerastium sp. \\
\hline & & & & & & & & & & & & & & & & & & & $\rightarrow$ & & & & & & & & & & & & & & & & & & & & & & & & & Cruciferae sp. \\
\hline & & & & & & & & & & & & & & & & & & & & & & & & & & & $\rightarrow$ & $\rightarrow$ & $N$ & $\rightarrow$ & & & & & & & & & & & & & & Juncus sp. \\
\hline & $\rightarrow$ & & & & & & & & $\rightarrow$ & & & & & $n$ & & & & & & & & N & & $\rightarrow$ & $n-$ & $\rightarrow$ & & $\rightarrow$ & & & $\rightarrow$ & & & & & & & & & & & & & Labiatae \\
\hline & $\rightarrow$ & & & & & & & $n n$ & $N \rightarrow$ & & & & & & & & & & & & & - & 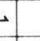 & & & & & & & & & & & & & & & & & & & & & Polygonaceae/Rumex sp. \\
\hline & & & & & & & & $\rightarrow$ & & & & & & & & & & & & & & & & & & & & & & & & & & & & & & & & & & & & Ranunculus sp. \\
\hline & & & & & & & & & & & & & & & & & & & & & & & & & $\rightarrow$ & & & & $\rightarrow$ & & & & & & & & & & & & & & & Rosaceae \\
\hline & & & & & & & & & & & & & & & & & & & & & & & & & & & & & $\rightarrow$ & $\rightarrow$ & $n$ & $\rightarrow$ C & $\omega$ & & & & & & & & & & & Sambucus sp., Frag. \\
\hline & & & & $\rightarrow$ & $\rightarrow$ & & & & & & & & & & & & & & & & & & $\rightarrow$ & & & & & & & & $n$ & & & & & & & & & & & & & Scrophularia nodosa /umbrosa \\
\hline$\rightarrow$ & & & & & & & & & & & & & & & & & & & & & & $N$ & $\rightarrow$ & $\rightarrow$ & $n-$ & $\rightarrow$ & & & & & & n & & & & & & & & & $\rightarrow$ & & - & $\rightarrow$ Umbelliferae \\
\hline & $\rightarrow$ & & & $\rightarrow$ & & & & & & & & & $\rightarrow$ & & & & & & & & & & & & & & & & & & & & & & & & & & & & & & & Viola sp. \\
\hline+ & + & ++ & ++ & + & + & + & +3 & $\mp$ & + & & 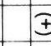 & $\Phi+$ & $+\mp$ & + & + & + & ++ & + & + & + & $\mp$. & ++ & ++ & + & + & ++ & ++ & + & + & + & + & ++ & + & + & $\mp$ & & & I & \pm & & ++ & + & + & + HK (Iverkohlte Materie) \\
\hline & & & & & & & & & & & & & & & & $\rightarrow$ & & & & $\rightarrow$ & & $v$ & $\rightarrow$ & $\overrightarrow{0}$ & or & $\omega$ & & & & & & & & & & & & & & & जा & & $\omega$ & Halmknoten/Halmfrag. verk. \\
\hline+ & + & ++ & ++ & + & + & + & + & + & ++ & + & + \pm & \pm+ & & + & + & + & ++ & + & + & + & + & ++ & ++ & + & + & ++ & + & & & & \pm &. \pm & + & + & ++ & & & & & $\mp$ & ++ & + & + & + Insektenreste \\
\hline
\end{tabular}


Tab. 3: Übersicht der durch pflanzliche Großreste nachgewiesenen Vegetationsgruppen (Kap. 3)

Table 3: Vegetation groups identified through botanical macro remains (see chapter 3) and their possible

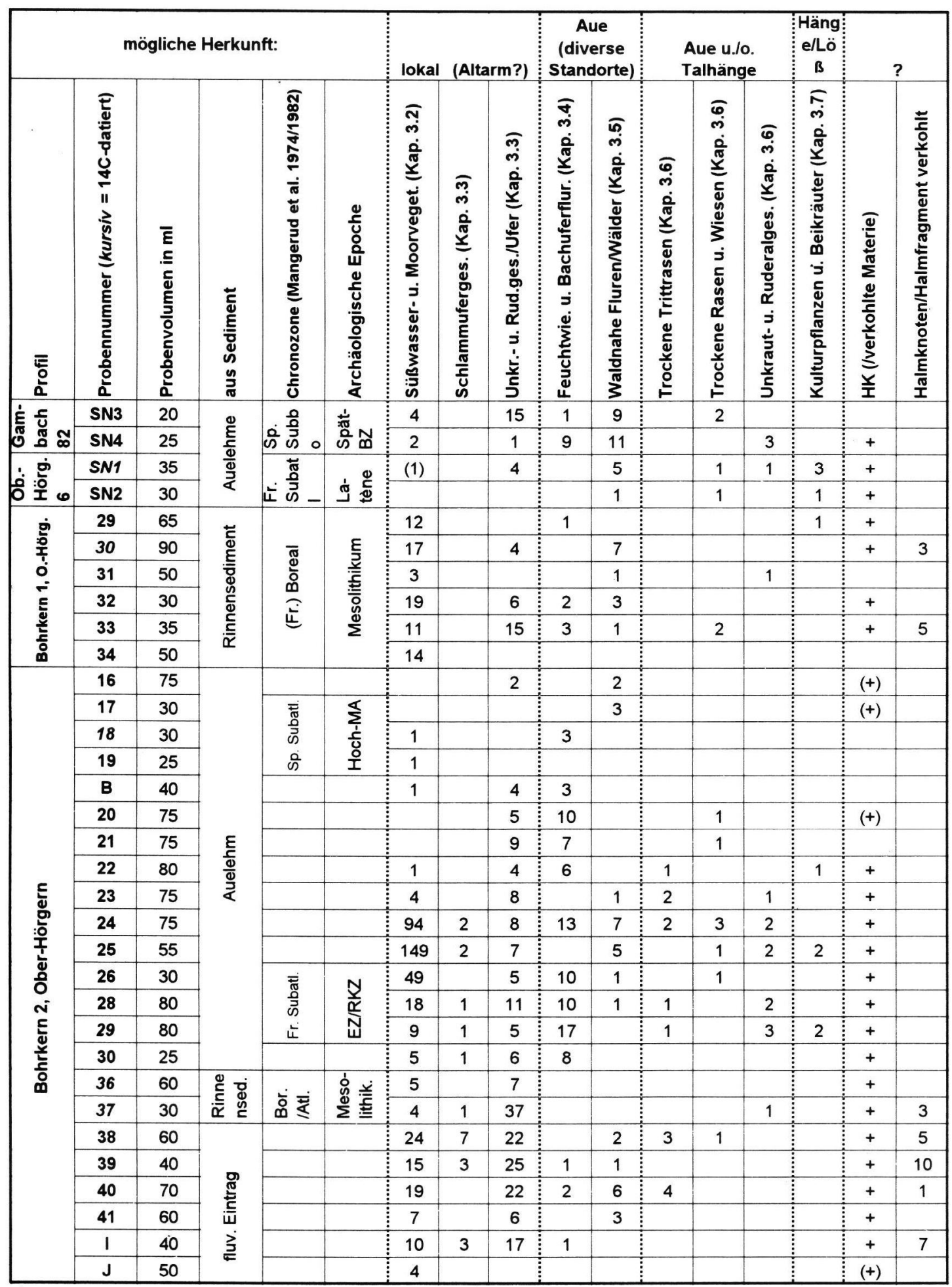


und ihrer möglichen Position innerhalb des Wettertales. Legende: vgl. Tabelle 2. location in the Wetter valley. Legend: see Table 2 .

\begin{tabular}{|c|c|c|c|c|c|c|c|c|c|c|c|c|c|c|c|c|}
\hline \multicolumn{6}{|c|}{ mögliche Herkunft: } & \multicolumn{3}{|c|}{ lokal (Altarm?) } & \multicolumn{2}{|c|}{$\begin{array}{c}\text { Aue } \\
\text { (diverse } \\
\text { Standorte) }\end{array}$} & \multicolumn{3}{|c|}{$\begin{array}{l}\text { Aue u.lo. } \\
\text { Talhänge }\end{array}$} & \multirow[b]{2}{*}{ 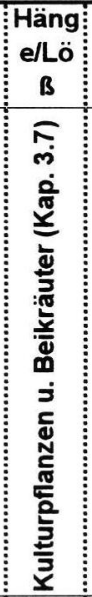 } & \multicolumn{2}{|c|}{ ? } \\
\hline \multirow[t]{2}{*}{ 등 } & 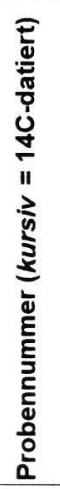 & 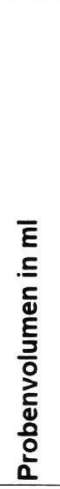 & 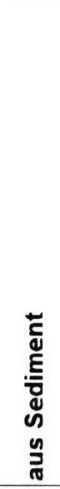 & 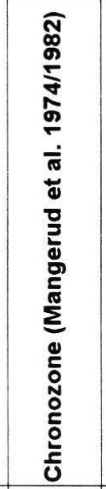 & 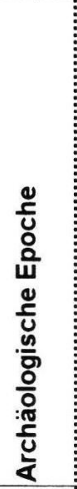 & 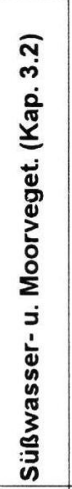 & 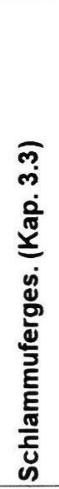 & 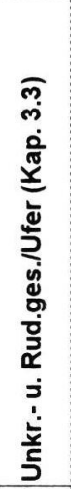 & 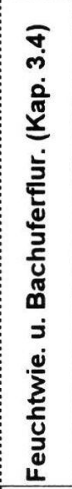 & 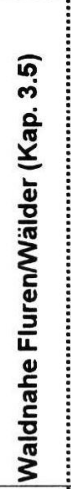 & 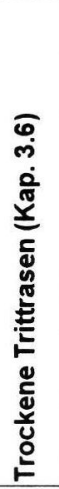 & 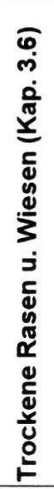 & 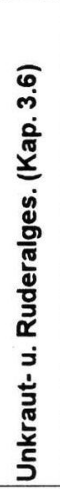 & & 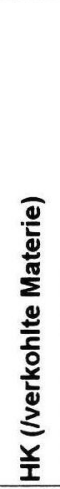 & 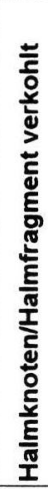 \\
\hline & 42 & 50 & & & & 13 & 1 & 11 & & 3 & 1 & & & & + & 1 \\
\hline \multirow{7}{*}{ 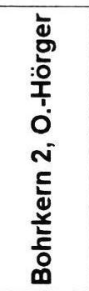 } & $k$ & 75 & \multirow{7}{*}{ 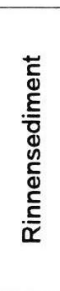 } & \multirow{7}{*}{ 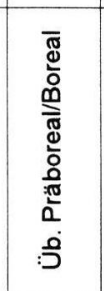 } & \multirow{7}{*}{ 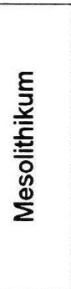 } & 17 & & 3 & 1 & & & & & & + & \\
\hline & $\mathbf{L}$ & 60 & & & & 21 & & 5 & 2 & & & & & & + & \\
\hline & 43 & 65 & & & & 6 & & 2 & & & & & & & + & \\
\hline & M & 70 & & & & 5 & & 2 & & & & & & & + & \\
\hline & 44 & 70 & & & & 12 & & 1 & & & & & & & + & 1 \\
\hline & $\mathbf{N}$ & 75 & & & & 10 & & 2 & & & & & & & + & \\
\hline & 45 & 70 & & & & 14 & & 3 & & & & & & & + & \\
\hline \multirow{17}{*}{ 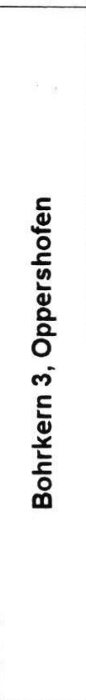 } & 26 & 75 & \multirow{12}{*}{ 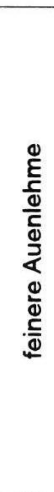 } & & & & & 1 & & & & & & & $(+)$ & \\
\hline & 27 & 35 & & & & 1 & & & & & & & & & + & \\
\hline & 28 & 50 & & & & 1 & & & & & & & & & $(+)$ & \\
\hline & 29 & 45 & & & & 1 & & 1 & & & & & & & & \\
\hline & 30 & 40 & & \multirow{5}{*}{ 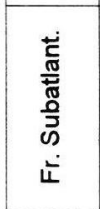 } & \multirow{5}{*}{ 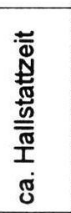 } & & & 2 & & 2 & & & & & & \\
\hline & 31 & 55 & & & & 1 & & 4 & 3 & & & & & & + & \\
\hline & 32 & 55 & & & & 6 & & 8 & 6 & & 1 & & & & & \\
\hline & 33 & 50 & & & & 1 & & & & & & & & & $(+)$ & \\
\hline & 35 & 65 & & & & 3 & & 4 & 3 & & 1 & & 1 & & + & \\
\hline & 36 & 45 & & & & 2 & 1 & 2 & 2 & & 1 & & 1 & 1 & + & \\
\hline & 37 & 70 & & & & 1 & 1 & 8 & 2 & 1 & & & & & + & \\
\hline & 38 & 50 & & & & 2 & 2 & 7 & 4 & 2 & & & 1 & & + & \\
\hline & 39 & 25 & $\bar{E}$ & & & 4 & & 9 & 2 & & & & & & + & \\
\hline & 40 & 80 & $\stackrel{\circ}{c}$ & & & 8 & 1 & 10 & & 1 & 2 & 1 & 3 & & + & \\
\hline & 41 & 60 & $\frac{0}{3}$ & & & 5 & 2 & 5 & 4 & 2 & & & & 1 & + & \\
\hline & 42 & 60 & 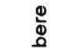 & 용 & $I$ & 3 & 1 & 7 & 1 & & & & 1 & & + & \\
\hline & 47 & 40 & 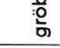 & 心 & ญ் & 2 & & 2 & & 2 & & & & & + & \\
\hline $\mathrm{nm}$ & & & chw & & & 642 & 30 & 354 & 137 & 83 & 20 & 15 & 23 & 11 & & \\
\hline & & & Arte & & & 20 & 5 & 16 & 10 & 12 & 3 & 9 & 9 & 6-7 & & \\
\hline
\end{tabular}


in atlantischen und älteren Abschnitten der Bohrkerne. Es fehlen in den älteren Bohrkern-Abschnitten auch Arten, die zum Beispiel in frühneolithischen (Mittleres Atlantikum) Siedlungen des Rhein-Main-Gebietes bereits häufig nachgewiesen wurden, wie Weißer Gänsefuß (Chenopodium album) oder Zwerg-Holunder (Sambucus ebulus; Kreuz 1990). Der heute als stark kulturabhängig geltende (KoRNECK \& SuKopp 1988) Weiße Gänsefuß ist entweder eine Anthropochore, oder die potentiellen, natürlichen Wuchsorte haben sich verändert und sind infolge menschlicher Eingriffe heute verschwunden. Leider ist die Datenbasis für eine weitergehende Interpretation zu gering

Auch Distel (Carduus crispus/acanthoides) und Vogelmiere (Stellaria media) gelten nach KorNECK \& Sukopp (1988) heute als stark kulturabhängig. Sie kommen in jüngeren Bohrkern-Abschnitten zur Zeit intensiver vor- und frühgeschichtlicher Besiedlung (u. a. Rupp 1991) in der Wetterau vor. Vielleicht haben sie sich sekundär - als Anthropochoren von anthropogenen Standorten (Wege, Schuttplätze, Viehläger, Äcker usw.) kommend - in der Ufervegetation des Wettertales angesiedelt. Andererseits besteht auch die Möglichkeit, daß die Kulturabhängigkeit dieser Arten erst seit dem Fehlen geeigneter natürlicher Standorte (Flurbereinigung, Gewässerbegradigung usw.) gegeben ist.

Die 41 Taxa der Vegetationsgruppen der Kap. 3.2 und 3.3 dürften in allen in den Bohrkernen erfaßten Zeitabschnitten im Ufer- oder Verlandungsbereich eines Altarmes oder eines langsam fließenden Mäanders vorgekommen sein (Tab. 3). Ob sie tatsächlich lokal bzw. extralokal aus der unmittelbaren Umgebung $(<570$ Meter) der Lokalität oder von weiter flußaufwärts (regionaler Eintrag) stammen, ließe sich nur mit der Untersuchung von Material aus Rasterbohrungen eingrenzen (vgl. z. B. CASPERS (1993) und die Beiträge in NeEdHAM \& Mackuin (1992). Einen lokalen oder extralokalen Eintrag spiegeln vermutlich auch die Reste von Mollusken, Fischen, Kleinsäugern und Insekten wider (Tab. 2).

\subsection{Feuchtwiesen und Bachuferfluren}

Es lassen sich zehn Arten - darunter 5 Pionierpflanzen - zusammenfassen, die außer in heutigen bewirtschafteten Grünlandgesellschaften (vor allem Molinietalia) gleichermaßen in Moorwiesen, Verlandungsbeständen, an Ufern und in Bruch- oder Auenwäldern auch ohne Zutun des Menschen verbreitet sind (Tab. 2). Dort können ihre Samen und Früchte bei Überflutungen erfaßt und abtransportiert werden.

Sumpfdotterblume (Caltha palustris), Blut-Weiderich (Lythrum salicaria), Sumpf-Ziest (Stachys palustris) und Gelbe Wiesenraute (Thalictrum flavum) fanden sich bereits in frühholozänen Profilabschnitten der Bohrkerne, in denen eine anthropogene Grünlandbewirtschaftung unwahrscheinlich ist (Tab. 2). Sie wuchsen daher in natürlichen Sumpfwiesen, Bruch- oder Auwald. Ein gehäuftes Auftreten solcher Arten in eisenzeitlichen und jüngeren Abschnitten läßt sich hingegen wohl - trotz der oben erwähnten Bedenken gegenüber quantitativer Auswertung - mit der damaligen Nutzung der Aue zunächst als Viehweide und einer später einsetzenden Wiesenbewirtschaftung erklären (vgl. auch Kap. 4). Einschürige Schnittwiesen sind seit der Römischen Kaiserzeit an Hand von pflanzlichen Großresten in der Wetterau nachgewiesen (Kreuz 1995a: 80).

\subsection{Waldnahe Staudenfluren, Gebüsche und Wälder}

Nur zwölf der gefundenen Arten gehören heute zu natürlichen, waldnahen Vegetationsgruppen oder Waldgesellschaften und dürften aus Gehölzbeständen des Wettertales eingetragen sein (Tab. 2). Auch hier gilt knapp die Hälfte der Taxa als Pionierpflanzen.

Besonders interessant sind die borealen und spätboreal-frühatlantischen Funde von Wildem Majoran (Origanum vulgare) und Arznei- oder SandThymian (Thymus pulegioides/serpyllum) in den Bohrkernen 1 und 2 (Abb. 5a u. b). Majoran und Thymian wuchsen möglicherweise in lichten Eichen- oder Kiefernwäldern auf trockenen Böden des Flußtales

Weitere mögliche Hinweise auf trockene, lichtreiche Wuchsorte in den Flußtälern oder an extrazonalen Standorten der Wetterau ergaben sich bereits im Rahmen einer archäobotanischen Untersuchung der neolithischen Fundstelle FriedbergBruchenbrücken (2. Hälfte 6. Jahrtausend v. Chr., Bandkeramische Kultur; Kreuz 1990: 27 u. 194, 1995: 126ff.). Die bandkeramische Siedlung liegt von den Entnahmestellen der Bohrkerne ca. 13 (Bohrkern 3) bis $18 \mathrm{~km}$ (Bohrkerne 1 u. 2) flußabwärts nahe der Wetter. Dort fanden sich Kiefer (Pinus cf. sylvestris), Wacholder (Juniperus communis), Flockenblume (Centaurea sp.), Hornkraut (Cerastium sp.), Augen- oder Zahntrost (Euphrasia vel Odontites sp.), Lieschgras (Phleum sp.), Gewöhnliches Bitterkraut (Picris hieracioides), Klappertopf (Rhinanthus sp.), Federgras 
(Stipa sp.), Klee (Trifolium sp.) und Königskerze (Verbascum sp.).

Bemerkenswert ist das weitgehende Fehlen (Tab. 2) von Funden der Schwarz-Erle (Alnus glutino$s a)$, deren Nüßchen in Auensedimenten ab der Chronozone Atlantikum eigentlich zahlreich zu erwarten gewesen wären (Kap. 5). Erle fehlt auch unter den (Brenn-)Holzkohlen der oben erwähnten Siedlung bei Friedberg-Bruchenbrücken, ist aber in jüngeren vorgeschichtlichen Siedlungen der Wetterau vorhanden (Kreuz unpubl.). In spätatlantisch-/früh-subborealen Sedimenten des Wettertales bei Friedberg-Bruchenbrücken war gleichfalls Erle neben Pappel (Populus sp.), Eiche (Quercus sp.), Kernobstgewächsen (Pomoideae)
A

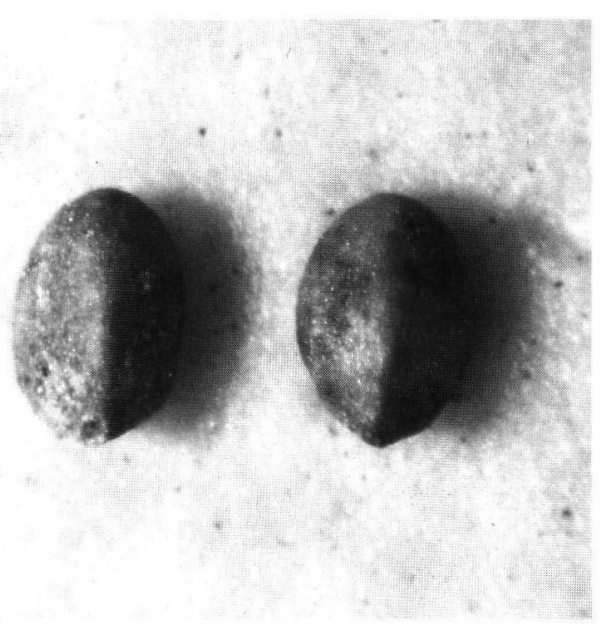

C

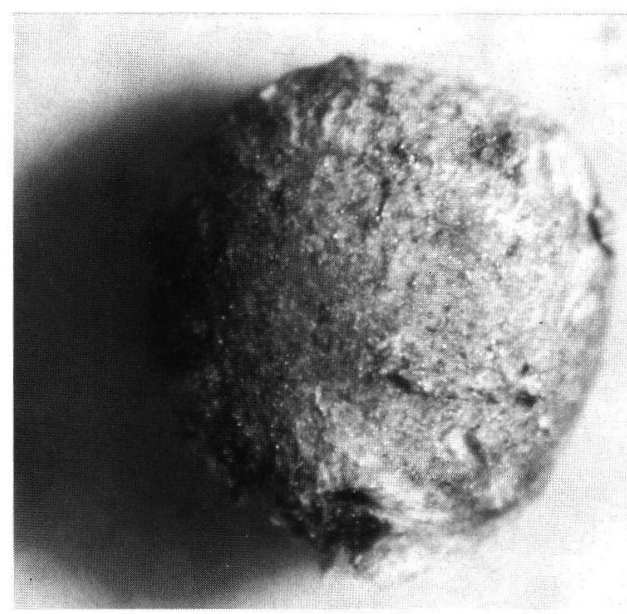

$\mathrm{B}$

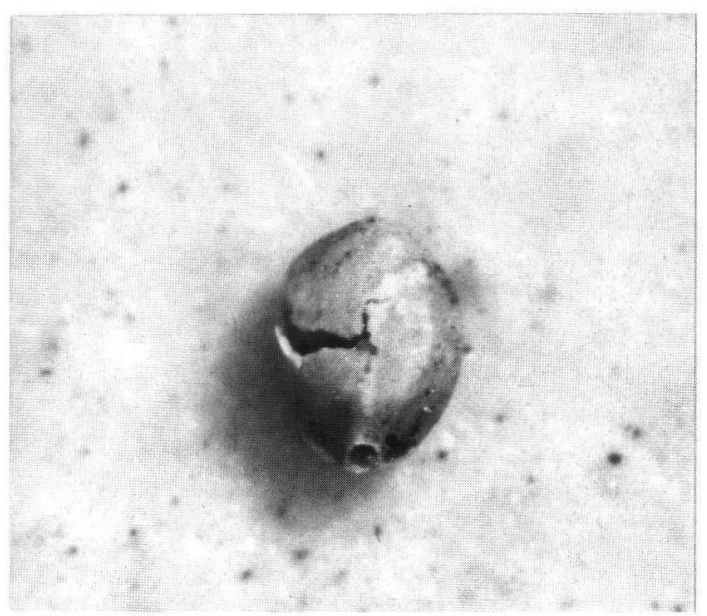

$\mathrm{D}$

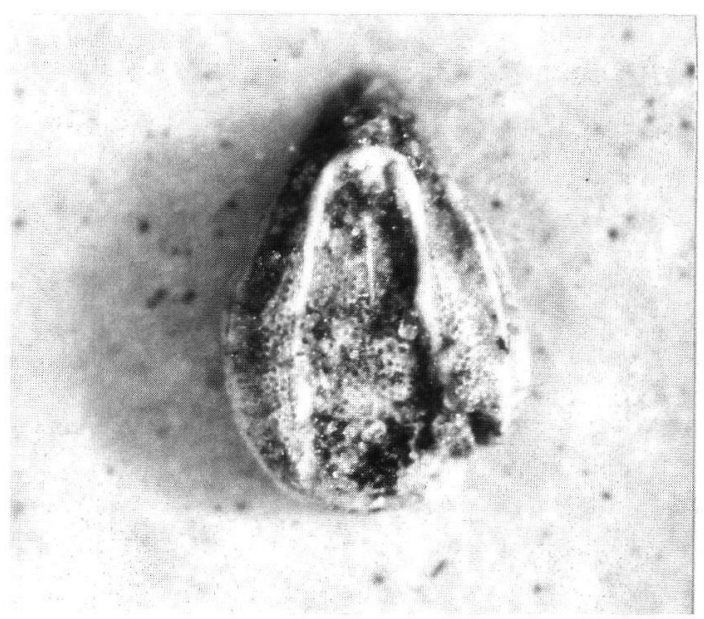

Abb. 5: Unverkohlte, subfossil erhaltene Früchte von a Origanum vulgare, b Thymus pulegioides/serpyllum, c Salvia cf. pratensis, d Valerianella dentata (a Bohrkern 1, Proben-Nr. Ohö4-33, Foto-Nr. 144-28, ventral, L rechts 0,8 mm; b Bohrkern 2, Ohö5-41, 141-30, ventr., L 0,8 mm; c Bohrkern 1, Ohö433, 142-16, ventr. L 1,6 mm; d Bohrkern 2, Ohö5-28, 144-35, ventr., L 1,4 mm).

Fig. 5: Uncharred subfossil fruits of a Origanum vulgare, b Thymus pulegioides/serpyllum, c Salvia cf. pratensis, d Valerianella dentata (a core 1, sample no. Ohö4-33, photo no. 144-28, ventral: length right $0.8 \mathrm{~mm}$; b core 2, Ohö5-41, 141-30, ventr., 1. $0.8 \mathrm{~mm}$; c core 1, Ohö4-33, 142-16, ventr., 1. $1.6 \mathrm{~mm}$; d core 2, Ohö5-28, 144-35, ventr., l. $1.4 \mathrm{~mm}$ ). 
und Ahorn (cf. Acersp.) bestimmbar (Kreuz 1990: 59ff.). Die Ausbreitung der Erle scheint sich nach den pollenanalytischen Ergebnissen in Hessen frühestens im Atlantikum zu vollziehen (SCHÄFER 1996: 131, dort weitere Literaturangaben; Sтовве 1996; URz 1995: 180ff.). Erhebliche regionale Unterschiede zeichnen sich $\mathrm{ab}$, die vor allem lokal - durch die jeweiligen standörtlichen Gegebenheiten - bedingt sein dürften.

Auch Großreste von Pappel und Weide (Populus sp., Salix sp.) als Bestandteile einer Weichholzaue fehlen in den Bohrkernen. Dies entspricht gleichfalls den Ergebnissen von URz (1995: 180ff.) im Lahntal: Er nimmt sogar an, daß sich dort eine Weichholzaue - mit Pappeln und Weiden - nicht vor dem Subatlantikum ausbildete. Pappel trat als Holzkohle in der neolithischen Siedlung bei Friedberg-Bruchenbrücken auf (Mittleres Atlantikum), Weide konnte noch nicht erfaßt werden.

Nach den Ergebnissen von NolTE (in Vorber.) wird die Wetter heute über weite Strecken von einem auch bei Spitzenhochwässern trockenen, mehrere 10 Meter breiten Uferwall gesäumt. Demnach liegen die potentiellen Wuchsorte für einen Weichholzauenwald nicht in Flußnähe, sondern eher am Auenrand (ablagerungsfern?), da erst hier das Hoch- und Grundwasser standörtlich wirksam wird. Eine solche Uferwallbildung wäre $a b$ dem Beginn der Ablagerung feinkörniger Auensedimente in einem mäandrierenden Flußsystem denkbar.

Bestandteile der Hartholzaue könnten außer Erle die Funde von Eiche und Schlehe sowie Schwarzem Holunder und Bittersüßem Nachtschatten gewesen sein (Tab. 2). Die geringe Zahl der Gehölznachweise (Großreste) aus den Bohrkernen überrascht, da im Tiefland in Flußtälern natürlicherweise ein hoher Gehölzanteil in Form von sogenannten Auen- und Bruchwäldern zu erwarten wäre, ganz im Gegensatz zur heutigen von Menschen geformten Vegetation (Kap. 5 u. 6).

\subsection{Arten trockener Standorte}

Drei weitere Gruppen von Pflanzenarten gedeihen nicht im unmittelbaren Überflutungsbereich der Aue, sondern sind auf trockenen Mineralböden des Flußtales (Talhänge, Uferwälle usw.) oder den angrenzenden Lößflächen anzusiedeln.

\section{Trittrasen nährstoffreicher Lehm- und Tonböden}

Die in in ausdauernden Trittrasen nährstoffreicher Lehm- u. Tonböden (Plantaginetea) vorkommenden drei Arten (Tab. 2) zeichnen sich insbe- sondere durch eine Unempfindlichkeit gegen Tritt aus, was ihnen - bei nur wenigen Konkurrenten - einen hohen Lichtgenuß verschafft. Gleichzeitig benötigen zum Beispiel Arten wie Vogel-Knöterich (Polygonum aviculare agg.) und Einjähriges Rispengras ( $\mathrm{Ooa}$ annua) Feuchtigkeit oder Nässe zum Keimen (ElLENBERG 1996: 849).

Vogel-Knöterich tritt schon im früh-atlantischen Abschnitt des Bohrkerns 2 auf (Tab. 2). Er könnte zum Beispiel an stark frequentierten, wassernahen Wildwechseln gewachsen sein. Alle drei Arten sind jedenfalls nach KornecK \& SuKopp (1988) nicht kulturabhängig, so daß mit ihrem natürlichen Vorkommen im Wettertal zu rechnen ist.

\section{Trockene Rasen und Wiesen}

Neun Arten finden sich heute in trockenen, anthropo-zoogenen Rasen- und Grünlandgesellschaften (Sedo-Scleranthetea, Festuco-Brometea, Molinio-Arrhenatheretea; Tab. 2). Die Funde von Wiesen-Salbei (Salvia cf. pratensis) und Feldsalat (Valerianella dentata) in Bohrkern 1 und 2 (Abb. $5 \mathrm{c}$ u. d, Tab. 2) geben einen weiteren Hinweis, daß im Boreal und frühen Atlantikum ihren Bedürfnissen entsprechende, lichte und trockene Standorte im Wettertal vorhanden waren (Kap. 3.5). Feldsalat gilt nach KorNECK \& SuKOpp (1988) heute als kulturabhängig. Wie oben ausgeführt, müssen wir mit andersartigen Standort- und damit Konkurrenzbedingungen in älteren Abschnitten des Holozäns rechnen, möglicherweise überformt durch anthropogene (mesolithische) Aktivitäten (Kap. 6).

Eine spätere vor- und frühgeschichtliche Nutzung des Wettertales als Viehweide und Wiesenstandort ist wahrscheinlich (Kap. 3.4) und wird durch die Großrest- und Pollenfunde bestätigt (Kap. 4 und 5).

\section{Unkraut- und Ruderalgesellschaften}

Neun Arten (Tab. 2) wachsen heute in verschiedenen, meist lückigen, Unkraut- und Ruderalgesellschaften (Chenopodietea, Artemisietea) auf nährstoffreichen, eher frischen Böden. Diese Arten sind nach KORNECK \& SuKOPP (1988) bis auf die Pionierpflanzen Hirtentäschel (Capsella bursapastoris) und Rainkohl (Lapsana communis) stark kulturabhängig. Ein natürlicher Wuchsort ist in Mitteleuropa heute unbekannt (OBERDORFER 1990). Womöglich handelt es sich bei diesen Taxa tatsächlich um Zeiger anthropogener Aktivitäten, die mit den subborealen und subatlantischen Auensedimenten zur Ablagerung gelangten (Tab. 2). Leider sind sie aber nicht an so charakteristi- 
sche Standorte gebunden, daß sich ihr Wuchsort genauer eingrenzen ließe. So muß offen bleiben, ob sie aus dem Wettertal oder von den Lößflächen eingetragen sind.

Nur der Schwarze Nachtschatten (Solanum nigrum) fand sich bereits in borealen und spät-boreal/früh-atlantischen Abschnitten der Bohrkerne 1 und 2. Er tritt auch in frühneolithischen (Mittleres Atlantikum) Siedlungen häufig auf und wurde dort aber als Anthropochore interpretiert (KREUZ 1990, 1993A).

\subsection{Kulturpflanzen und Beikräuter}

Wie die ökologische und pflanzensoziologische Gruppierung der durch Großreste nachgewiesenen Taxa zeigt, haben wir es bei den drei Bohrkernen mit allochthonen Ablagerungen zu tun, deren Pflanzenreste aus unterschiedlichen Bereichen des Flußtales, vor allem aber aus der Aue, stammen dürften (Thanatocoenosen). Es treten zu den regelmäßig vorhandenen Funden einer Süßwasser- und Moorvegetation in der Regel noch Reste angrenzender, seltener auch trockener Standorte hinzu, die wohl bei Überstauung der Ablagerungen infolge Hochwassers eingetragen wurden (Tab. 2 u. 3).

Die Ablagerung von Pflanzenresten in alluvialen Sedimenten kann unmittelbar mit menschlichen Aktivitäten (einschließlich Viehzucht) in den umliegenden und flußaufwärts befindlichen Nutzungsräumen verknüpft sein. Je kleiner das Fließgewässer, desto geringer ist allerdings der zu erwartende Ferntransport. Der Eintrag ist also abhängig von der Größe des Einzugsgebietes, somit der Größe und Art des Flußsystems sowie der Nähe zu menschlichen (und tierischen) Aktivitäten.

Die überwiegenden Abschnitte der Bohrkerne datieren in vor- und frühgeschichtliche Epochen (Vorrömische Eisenzeit, Römische Kaiserzeit, Mittelalter), in denen aus den an das Wettertal angrenzenden Lößlandschaften ackerbauliche und andere anthropogene Aktivitäten durch zahlreiche archäologische und naturwissenschaftliche Untersuchungen belegt sind (u. a. Kreuz 1990, 1993b, 1995a; Rupp 1991; Saile 1992; STOBвE 1996). Dennoch fanden sich - ganz im Gegensatz zu den pollenanalytischen Ergebnissen (Kap. 4) - in 145 untersuchten Sedimentproben nur vereinzelte Großreste von drei Kulturpflanzenarten: zwei verkohlte Körner der Gerste (Hordeum sp.), ein verkohltes Korn von Weizen (Triticum sp.), eine verkohlte Hüllspelzenbasis von Emmer oder Dinkel (Triticum dicoccum/spelta) und ein unverkohlter Samen von Schlafmohn (Papaver somni- ferum). Diese werden ergänzt von nur einem unverkohlten Beleg eines eindeutigen Ackerunkrautes, dem Winden-Knöterich (Polygonum convolvulus). Der geringe oder fehlende Anteil nicht im Wettertal vorkommender Arten unter den pflanzlichen Großresten gibt einen Hinweis auf die Flußdynamik und anthropo(-zoo)gene Einflüsse.

Heute finden sich im Wettertal nach Winter- und Frühjahrshochwässern im flachen Auenbereich Spülsäume, die nach eigenen Untersuchungen zahlreiche Überreste von Feld- und Gartenfrüchten wie auch von anderen Arten, die in der Aue selbst nicht wachsen, enthalten. Sie gelangen dort zusammen mit Siedlungsabfällen (Plastik, Kronkorken usw.) zur Ablagerung. Es überrascht, daß ein solcher regionaler Eintrag in den subborealen und subatlantischen Abschnitten der Bohrkerne weitestgehend fehlt. Gleichzeitig fällt auf, daß in den Sedimentproben sogar Reste der häufig (auch natürlich) in der Aue vorkommenden Gehölze (z. B. Erle, Hasel, Eiche, Schlehe) kaum vertreten sind, obwohl deren verholzte Fruchtsteine, Nußschalen usw. vergleichsweise besonders gut erhaltungsfähig sind (Kap. 3.5 und 5).

Dies entspricht auch den Ergebnissen von ARORA et al. (1995) im Elsbachtal, Rheinland. Dort wurden an Gehölzen nur Birke (Betula sp.), Erle ( $\mathrm{Al}$ nus glutinosa), Brombeere und Himbeere (Rubus fruticosus, $R$. idaeus) durch Großreste nachgewiesen, obwohl diese spätkaiserzeitlichen und frühmittelalterlichen Ablagerungen nach den Pollenanalysen in einer waldreichen Landschaft entstanden. Kulturpflanzen fehlen dort sogar gänzlich. Ähnliche Ergebnisse erbrachte auch die Untersuchung eines Neckaraltarmes bei RiedstadtGoddelau, Oberrheinebene (Grosse-BrauckmanN et al. 1990).

Da Pflanzenreste grundsätzlich einer relativ raschen Zersetzung unterliegen, wenn sie sich nicht im Grund- oder Stauwassereinflußbereich befinden, müßten alle Vegetationsgruppen von der Zersetzung gleichermaßen betroffen sein und nicht selektiv Kulturpflanzen und ihre Beikräuter sowie Gehölze. Möglicherweise waren die Eintragswege erodierten Materials (u. a. Kulturpflanzenreste) von den Lößflächen in die Aue in vorund frühgeschichtlichen Epochen noch nicht im heutigen Umfang gegeben oder sie verliefen andersartig als heute. Gleichzeitig scheint die Gehölzvegetation (anthropogen bedingt?) stark reduziert gewesen zu sein. 
Tab. 4: Nachgewiesene Pollen- und Sporentaxa mit ihren prozentualen Anteilen aus Bohrkern 2 (mit * gekennzeichnet) berechnet. Die Werte der Wasser- und Sumpfpflanzen wurden auf diese rundet, daher können Rundungsfehler auftreten. Fettgedruckte Taxa sind im Bohrkern 2 auch durch Table 4: Identified taxa of pollen and spores with their percentages in core 2 near Ober-Hörgern. The per: centages were rounded to one decimal place. Taxa in bold letters were also indentified by macro remains

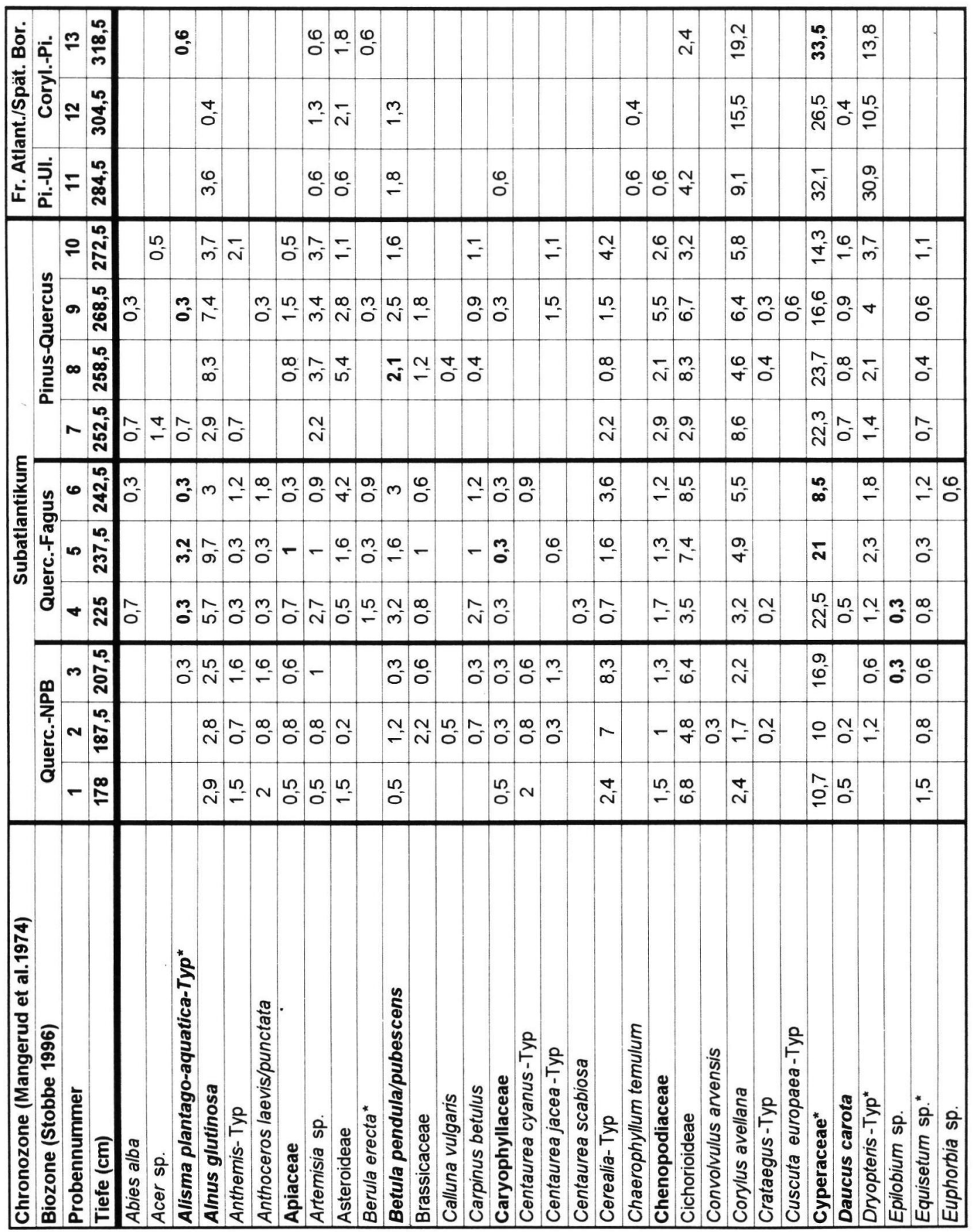


bei Ober-Hörgern. Die Prozentwerte sind auf eine Pollensumme ohne Wasser- und Sumpfpflanzen Pollensumme bezogen. Die Prozentangaben wurden programmbedingt auf eine Dezimalstelle gepflanzliche Großreste nachgewiesen (vgl. Tab. 2).

centages were calculated based on a pollen sum without water or fen plants (marked *). The pollen per-

in cross-section 2 (see Table 2).

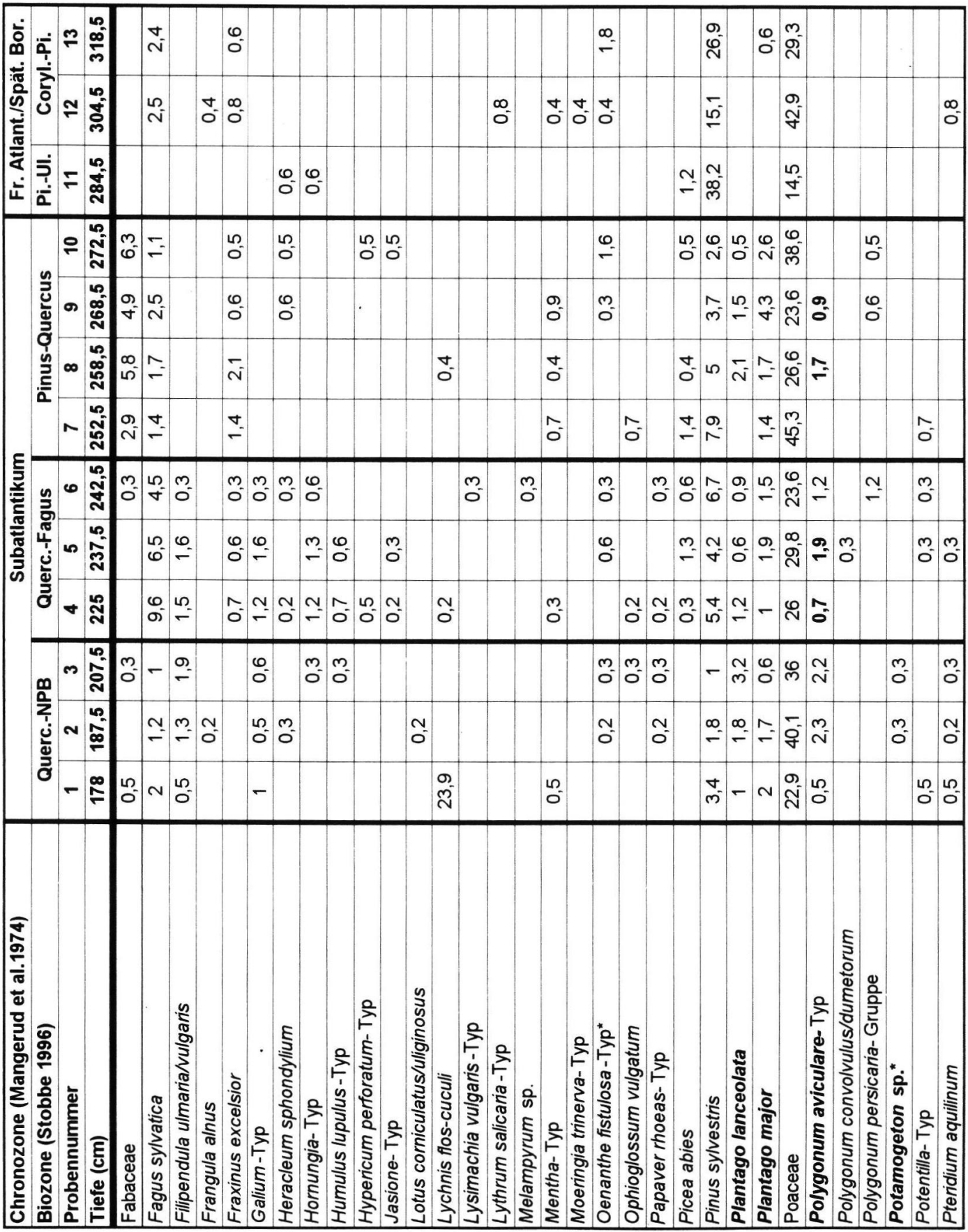




\begin{tabular}{|c|c|c|c|c|c|c|c|c|c|c|c|c|c|}
\hline \multirow{3}{*}{\begin{tabular}{|l|} 
Chronozone (Mangerud et al.1974) \\
Biozone (Stobbe 1996) \\
Probennummer
\end{tabular}} & \multicolumn{10}{|c|}{ Subatlantikum } & \multicolumn{3}{|c|}{ Fr. Atlant./Spät. Bor. } \\
\hline & \multicolumn{3}{|c|}{ Querc.-NPB } & \multicolumn{3}{|c|}{ Querc.-Fagus } & \multicolumn{4}{|c|}{ Pinus-Quercuś } & \multirow{2}{*}{\begin{tabular}{|c|} 
Pi.-Ul. \\
11
\end{tabular}} & \multicolumn{2}{|c|}{ Coryl.-Pi. } \\
\hline & 1 & 2 & 3 & 4 & 5 & 6 & 7 & 8 & 9 & 10 & & 12 & 13 \\
\hline Tiefe $(\mathrm{cm})$ & 178 & 187,5 & 207,5 & 225 & 237,5 & 242,5 & 252,5 & 258,5 & 268,5 & 272,5 & 284,5 & 304,5 & 318,5 \\
\hline Quercus sp. & 4,9 & 4,3 & 3,2 & 7,1 & 8,4 & 6,7 & 4,3 & 10,4 & 4,6 & 5,3 & 6,1 & 5 & 7,8 \\
\hline Ranunculus sp. & & 1,3 & 4,5 & 0,5 & 0,3 & 1,2 & 0,7 & & 1,2 & & 0,6 & & \\
\hline Ranunculus acris- Gruppe & & 2,2 & & & 0,3 & 0,9 & & & 0,3 & & & & \\
\hline Riccia-Typ & 2 & 0,8 & 1 & & 0,3 & 0,9 & & & 0,6 & & & & \\
\hline Rosaceae & & 0,2 & & 0,3 & & & & & & & & & \\
\hline Rumex sp. & 2 & 1 & 1 & 1,4 & & 0,6 & 0,7 & & 1,2 & & & & 0,6 \\
\hline Salix spec. & 1,5 & 0,2 & 1,3 & 5,6 & 0,3 & 2,7 & & & 0,6 & 2,1 & & & 0,6 \\
\hline Sambucus nigra -Typ & & & & 1 & 0,3 & 0,3 & 1,4 & & & 1,1 & & 0,8 & \\
\hline Sanguisorba minor & & & & & & & 0,7 & & & & & & \\
\hline Sanguisorba officinalis & & & & 0,2 & & & & & & & & & \\
\hline Sarothamnus scoparius & & 0,2 & & & & & & & & 0,5 & & & \\
\hline Scleranthus annuus/perennis & & & & & & & & & 0,3 & & & & \\
\hline Secale cereale-Typ & 5,4 & 9,5 & 8 & 0,5 & 1,3 & 3,3 & & & 0,6 & & & & \\
\hline Solanum dulcamara & & & & 0,5 & 0,3 & & & & & & & 0,4 & 0,6 \\
\hline Sparganium sp.* & 1 & 1 & 2,5 & 1 & 1,6 & 1,5 & & 0,4 & & & 4,8 & 0,8 & 6,6 \\
\hline Spergula -Typ & & 0,5 & & & & & & & & & & & \\
\hline Sphagnum sp.* & 0,5 & & 0,3 & 0,2 & 0,3 & & & & & & & 0,4 & \\
\hline Symphytum officinale- Typ & & 0,2 & 0,3 & & & & & 0,4 & & & & & \\
\hline Tilia sp. & 0,5 & & 0,6 & 1,2 & & 0,9 & 2,2 & 0,8 & 0,9 & 1,6 & 9,7 & 1,7 & 1,2 \\
\hline Trifolium pratense- Typ & & & & 0,2 & & & & & & & & & \\
\hline Trifolium repens-Typ & & & & & & 0,3 & & & & 0,5 & & & \\
\hline Typha angustifolia* & & & & & & & & & & & & 0,4 & \\
\hline Typha latifolia* & & & 0,3 & 0,3 & 0,3 & 0,6 & & & 0,3 & 1,1 & 0,6 & 2,9 & \\
\hline Ulmus sp. & & 0,2 & & 0,5 & & 0,3 & & 1,2 & 0,6 & 0,5 & 6,7 & 5,9 & 4,8 \\
\hline Urtica dioica & & 0,2 & 0,6 & 0,3 & 0,3 & 0,6 & 0,7 & 0,4 & 0,3 & & & 0,8 & \\
\hline Valeriana officinalis- Gruppe & & & & 0,2 & & & & & & 0,5 & & & \\
\hline Veronica-Typ & & & 1,9 & 1,2 & 1 & 0,3 & & & & 0,5 & & & \\
\hline Vicia cracca-Typ & & & & & & & 0,7 & & & & & & \\
\hline Pollensumme ohne Sumpf- u.Wasserpfl. & 205 & 598 & 314 & 592 & 309 & 330 & 139 & 241 & 326 & 189 & 165 & 238 & 167 \\
\hline Gesamtpollensumme & 233 & 679 & 384 & 759 & 402 & 380 & 175 & 305 & 402 & 230 & 278 & 339 & 262 \\
\hline
\end{tabular}




\section{Pollenanalytische Ergebnisse}

(A. STOBBE)

\subsection{Methode}

Pollenanalysen an fluviatilen Ablagerungen sind mit vielfachen Fehlerquellen behaftet. Neben häufigen Fazieswechseln und Sedimentlücken (Hiaten) sind oftmals mächtige mineralische, weitgehend sterile Einschwemmungen in den Ablagerungen vorhanden, die eine durchgängige palynologische Auswertung unmöglich machen (Moore et al. 1991: 25). Da im vorliegenden Fall aufgrund eines vielgestaltigen Ausleseprozesses während der Sedimentation sowohl in qualitativer als auch in quantitativer Hinsicht mit großen Unregelmäßigkeiten zu rechnen war, erschien die Erstellung eines Pollendiagramms nicht sinnvoll. Dennoch weicht die Pollenvergesellschaftung in den einzelnen Zeitabschnitten von den Ergebnissen der bisher vorliegenden Pollendiagramme der Wetterau (STOBBE 1995, 1996; BunNIK et al. 1995) nur unwesentlich ab, so daß durchaus eine Interpretation der pollenführenden $\mathrm{Ab}$ schnitte berechtigt erscheint. Die nachgewiesenen Arten sind mit ihrem prozentualen Anteil in Tab. 4 zusammengefaßt. Als Herkunftsort der Pollenkörner kommt die lokale Vegetation des untersuchten Standortes, die extralokale Vegetation im Übergangsbereich von feucht zu trocken, die Vegetation der Wälder und Wirtschaftsflächen auf den Lößflächen und schließlich in geringen Mengen die extraregionale, weit entfernte Vegetation in Frage.

Die mit einem Bohrzylinder aus Bohrkern 2 entnommenen Sedimentproben wurden in Natriumpyrosphat erhitzt, abgesiebt und mit 10\%iger Kalilauge versetzt. Es erfolgte eine Behandlung mit Flußsäure und anschließender Acetolyse. Die mikroskopische Bestimmung und Auszählung wurde bei 500 - bis 790facher Vergrößerung durchgeführt.

\subsection{Auswertung}

Die pollenführenden Abschnitte zeigten im vorliegenden Fall mitunter eine sehr schlechte Pollenerhaltung und Pollendichte (Tab. 4). Insgesamt wurden 13 Tiefen (Proben) pollenanalytisch ausgewertet, die aus drei verschiedenen Zeitabschnitten stammen. Ihre zeitliche Einordnung wird jeweils durch drei $14 \mathrm{C}$-Datierungen gestützt (Tab. 1). Die einzelnen Abschnitte sind in die regionale Pollenstratigraphie (Biozonen) der Wetterau (STовве 1995, 1996) eingeordnet worden.

Im folgenden werden die untersuchten Proben besprochen. Dabei wird für jeden Abschnitt zunächst die regionale Vegetation der Mineralbö- den erläutert und anschließend die Vegetation des unmittelbaren Auenbereichs dargestellt: Proben 13 und 12 stammen aus einem Übergangshorizont zwischen einer Rinnenfüllung und dem sogenannten Schwarzen Auenboden, Probe 11 aus dem Schwarzen Auenboden, die übrigen Proben aus Auenlehmen.

\section{Spätes Boreal/Frühes Atlantikum}

(318,5-284,5 cm, Proben 13-11)

Die unteren 2 Proben (13 und 12) können biostratigraphisch in die Corylus-Pinus-Zone gestellt werden, Probe 11 kann der Pinus-Ulmus-Zone zugerechnet werden (nach STOBBE 1996). Nach der chronostratigraphischen Gliederung von MANGerud et al. $(1974,1982)$ sind die Proben dem Abschnitt Spätes Boreal/Frühes Atlantikum zuzurechnen. Im Anschluß folgt ein Hiatus, der eine Zeitspanne von rund 6500 Jahren umfaßt. Die Pollenführung und Pollenqualität nimmt in den Pollenproben von Probe 13 zu Probe 11 deutlich ab. Im Schwarzen Auenboden oberhalb von Probe 11 waren keine Pollenkörner erhalten. Ein ganz ähnliches Phänomen hat sich bislang in nahezu allen Pollenprofilen aus der Wetterau in diesem Zeitbereich gezeigt. Am Ende des Boreals und im Atlantikum wurden vor allem anmoorige, für Pollenanalysen weniger geeignete Sedimente abgelagert, oder Sedimente fehlen sogar vollständig (Sтовве 1996: 22-24).

\section{Regionale Vegetation der Lößflächen}

Unter den Baumpollen, die klar im Pollenbild vorherrschen, dominiert die Kiefer, gefolgt von Hasel, Eiche, Linde und Ulme. In diesem Zeitabschnitt läßt sich in Mitteleuropa aufgrund der pollenanalytischen Ergebnisse eine Aufteilung der Landschaften in einen atlantisch getönten Bereich mit Haseldominanz und einen kontinental getönten Bereich mit hohen Kiefernwerten beobachten (FIrBAS 1949; LANG 1994). In der Wetterau sind im Boreal sehr hohe Kiefernwerte und relativ niedrige Haselwerte belegt (STOBвE 1996). Dies ist wahrscheinlich darauf zurückzuführen, daß es sich bei der Wetterau um eine trockene Beckenlandschaft handelt, deren Niederschläge in bestimmten Bereichen - und so auch bei Ober-Hörgern - heute die 500-550 mm Grenze nicht überschreiten (DEUTSCHER WETTERDIENST 1950). Da die Hasel höhere Niederschläge als die Kiefer benötigt, konnte sie sich möglicherweise auf den Lößflächen im Boreal nicht durchsetzen.

Pollenprobe 11 zeigt eine deutliche Zunahme der Linde, und erstmals ist die Fichte nachgewiesen. Diese Probe kann biostratigraphisch in die Pinus- 
Ulmus-Zone eingeordnet werden, die sich vor allem durch die stärkere Etablierung der Laubbäume auszeichnet (STOвве 1996).

\section{Lokale Vegetation der Aue}

Der Auenbereich war, von wenigen Weiden- und Holundersträuchern abgesehen, waldfrei, und es herrschten lichte, farnreiche Röhrichte mit Typha latifolia (Breitblättriger Rohrkolben), Sparganium sp. (Igelkolben), Alisma plantago-aquaticaTyp (Gewöhnlicher Froschlöffel), Oenanthe fistulosa-Typ (Wasserfenchel) und Berula erecta (Aufrechter Merk) vor. Dazwischen waren Seggenriede und Naßwiesen mit Hochstauden, z. B. Filipendula sp. (Mädesüß), Cichoriodeae (Zungenblütler) und Asteroideae (Röhrenblütler) eingeschaltet (Tab. 4). Die hier gefundenen niedrigen Erlenwerte entsprechen den Ergebnissen von STOBBE (1996): Die Erle ist im späten Boreal und frühen Atlantikum in der Wetterau nur mit Einzelpollenkörnern nachweisbar, ihr Vorkommen dort um diese Zeit eher unwahrscheinlich.

\section{Späte Eisenzeit/Frühe Römische Kaiserzeit}

(272,5-252,5 cm, Proben 10-7)

Die vier ausgewerteten Pollenproben können biostratigraphisch in die Pinus-Quercus-Zone eingeordnet werden (Stobbe 1996), die in das Mittlere Subatlantikum datiert. Chronostratigraphisch müssen sie aufgrund der ${ }^{14} \mathrm{C}$-Daten in das Frühe Subatlantikum gestellt werden.

\section{Regionale Vegetation der Lößflächen}

Die Baumpollenwerte sind gegenüber den Spektren aus dem Boreal deutlich niedriger und zeigen, daß der Waldanteil in der Landschaft nun wesentlich geringer war. Die am häufigsten nachgewiesenen Pollentypen stammen von Hasel, Eiche, Buche und Erle. In der potentiell natürlichen Vegetation der Wetterau würden auf den Lößflächen in dieser Periode Buchenwälder vorherrschen (BOHN 1981). Diese natürlichen Waldgesellschaften existierten zum Zeitpunkt der Ablagerung jedoch nicht mehr flächendeckend, sondern waren nur noch in Restbeständen im Gebiet der zentralen Wetterau vorhanden (STOBвE 1996). $\mathrm{Da}$ die Buchenstandorte zugleich die besten Ackerbauflächen darstellten, sind die niedrigen Fagus-Werte vor allem in Verbindung mit einer intensiven Landwirtschaft auf den Lößflächen zu sehen.

Auch eine Vielzahl von Ackerbau anzeigenden Arten ist belegt. Cerealia-Pollenkörner und Seca$l e$-Pollenkörner sind nachgewiesen. Bei den ein- zelnen Roggenfunden dürfte es sich jedoch um Unkrautroggen handeln. $\mathrm{Zu}$ einem gezielten Anbau kam es in der Wetterau frühestens seit der Römerzeit (Kreuz 1995: 74ff.). Die Nachweise der Hornmoos-Sporen von Anthoceros laevis/ punctata sowie der Lebermoos-Sporen von Riccia deuten auf oft gestörte Plätze und brachliegende oder feuchte Lehmäcker hin. Sie gelten als Indikatoren intensiver Landwirtschaft (DiCKSON 1986; Jahns 1987; VAN GEeI. 1983).

Die hohe Zahl der Nichtbaumpollenkörner, bei denen die Ruderalpflanzen, z. B. Artemisia sp. (Beifuß), Chenopodiaceae (Gänsefußgewächse) und Urtica dioica (Große Brennessel) dominieren, spricht für das Vorhandensein freier, unbeschatteter Stellen mit hohem Nährstoffangebot auf den Lößflächen oder im Flußtal. Die Nachweise von Polygonum aviculare-Typ (VogelKnöterich-Gruppe) und Plantago major (Großer Wegerich) deuten auf Wege oder Viehtriften im Bereich der Ablagerung hin.

Lokale Vegetation der Aue

Im Bereich der Ablagerung wuchsen wenige Weiden- und Holundersträucher und auch weiterhin kamen Seggenriede und Röhrichte vor, deren Farnanteil nun deutlich niedriger ist. Als typische Röhrichtarten sind Oenanthe fistulosa-Typ (Wasserfenchel), Alisma plantago-aquatica-Typ (Gewöhnlicher Froschlöffel), Berula erecta (Aufrechter Merk), Typha latifolia (Breitblättriger Rohrkolben) und Sparganium sp. (Igelkolben) einzuordnen.

Arten des Grünlandes, wie Plantago lanceolata (Spitzwegerich), Centaurea jacea-Typ (cf. Wiesen-Flockenblume), Rumex (Ampfer), Ranunculus acris-Typ (Hahnenfuß), Daucus carota (Wilde Möhre), Lychnis flos-cuculi (Kuckucks-Lichtnelke), Trifolium repens-Typ, Vicia cracca-Typ und Symphytum officinale-Typ (Beinwell), sind vielfach belegt und zeigen, gemeinsam mit den hohen Werten der Gräser, daß es in dieser Periode zu einer starken Nutzung der Auenbereiche kam. Vor allem wechselfeuchte, ungedüngte Magerwiesen oder -weiden waren weit verbreitet (STOBBE 1996).

\section{Mittelalter}

(242,5 - $178 \mathrm{~cm}$, Proben 6 - 1)

Ab Probe 6 ist der Bohrkern aufgrund der drei Nachweise von Centaurea cyanus (Kornblume) wahrscheinlich nicht älter als die Merowingerzeit (500-700 AD). In älteren Abschnitten fehlt die Kornblume unter den Pollentypen (STовве 1996). 
Dies bedeutet, daß hier wahrscheinlich ein Hiatus von mehreren hundert Jahren vorliegt. Die unteren drei Proben ( 6 - 4) lassen sich biostratigraphisch in die Quercus-Fagus-Zone einordnen (STOBвE 1996), die der Merowingerzeit entspricht. Die oberen drei Proben (3 - 1) können in die Quercus-NBP-Zone gestellt werden, die mit der Karolingerzeit/Hochmittelalter zusammenfällt.

\section{Merowingerzeit}

(242,5 - $225 \mathrm{~cm}$, Proben 6 - 4)

Regionale Vegetation der Lößflächen

Eine biostratigraphische Einordnung der Proben 6 - 4 ist vor allem durch den Nachweis von Centaurea cyanus (Kornblume) und die höheren Roggenwerte möglich (STOBвE 1996). Es ist nun sicher mit dem Anbau von Roggen zu rechnen, vermutlich als Wintergetreide. An Unkräutern sind Polygonum convolvulus/dumetorum (wohl Winden-Knöterich) und Papaver rboeas-Typ (Mohn) erfaßt. Die Nachweise von Anthoceros und Riccia haben zugenommen. Polygonum aviculare-Typ und Plantago major sind weiter vorhanden und deuten auf viel betretene Standorte hin.

Insgesamt weicht das Pollenspektrum nur unwesentlich von dem des vorangegangenen $\mathrm{Ab}$ schnitts ab, so daß eine ähnliche Vegetation wie in der Späten Eisenzeit/Frühen Römischen Kaiserzeit angenommen werden kann.

\section{Lokale Vegetation}

Es zeigen sich erhöhte Werte von Salix sp. (Weide) und auch die Röhrichtarten Sparganium sp. (Igelkolben), Berula erecta (Aufrechter Merk) und Alisma plantago-aquatica-Typ (Gemeiner Froschlöffel) - letzterer auch als Großrest in dieser Probe verstärkt nachgewiesen - haben zugenommen. Der Röhrichtgürtel blieb in seiner Zusammensetzung weitgehend erhalten.

Karolingerzeit/Hochmittelalter (207,5-178 cm, Proben 3 - 1)

Regionale Vegetation der Lößflächen

Geringere Baumpollenwerte verweisen auf weitere Vegetationsveränderungen: Die Werte von Buche und Hainbuche sind deutlich niedriger. Die Esche ist nicht mehr nachweisbar. Zu dieser Zeit ist nur noch in den Randlagen der Wetterau mit mehr oder weniger dichten Wäldern zu rechnen, die ansonsten einer flächendeckenden Erschließung der Landschaft zum Opfer gefallen sind (STовве 1996). Erhöhte NichtbaumpollenWerte von Secale cereale-Typ, Cerealia, Centaurea cyanus, Papaver rhoeas-Typ oder Spergula-
Typ weisen auf eine Intensivierung des Ackerbaus hin. Das nun stetig vertetene Wintergetreideunkraut Centaurea cyanus-Typ (Kornblume) läßt auf verstärkten Wintergetreideanbau schließen.

Es sind erhöhte Pollenwerte der Grünlandarten zu beobachten. Plantago lanceolata (Spitzwegerich), Centaurea jacea-Typ (eine Flockenblume), Ranunculus acris-Gruppe (ein Hahnenfuß) und die Gräser haben zugenommen. In Probe 1 ist vor allem Lychnis flos-cuculi (Kuckucks-Lichtnelke) stark angestiegen und auch durch Großreste belegt (Tab.2).

Die lokale Vegetation der Aue scheint sich von der frühmittelalterlichen nicht wesentlich zu unterscheiden. Potamogeton (Laichkraut) ist nun erstmals nachgewiesen.

\section{Vergleich der Großrest- und Pollenanalysen}

(A. Kreuz \& A. STOBbe)

Ein Vergleich der Ergebnisse von Großrest- und Pollenanalysen (Kap. 3 und 4) ist im subatlantischen (mittelalterlichen und späteisenzeitlichrömerzeitlichen) und im spätboreal-/frühatlantischen (mesolithischen) Bereich des Bohrkerns 2 aus dem Auenquerprofil bei Ober-Hörgern möglich. Der den archäologischen Epochen Späte Bronzezeit bis Eisenzeit entsprechende Zeitabschnitt Ende Subboreal/Beginn Subatlantikum wurde in Bohrkern 3 sowie den Proben aus Gambach (Bohrung 82) und Ober-Hörgern (Bohrung 6) durch Großreste erfaßt.

Aus den spät-präboreal/früh-borealen Rinnensedimenten der Bohrkerne 1 und 2 liegen Samen und Früchte einer differenzierten Ufervegetation vor (Tab. 2). Stickstoffzeiger wie Typha sp., Eupatorium cannabinum, Urtica dioica und Myosoton aquaticum lassen mesotrophe Verhältnisse erwarten.

Im Spätboreal/Frühatlantikum handelt es sich in Bohrkern 2 um Sedimente aus einem Übergangsbereich zwischen einer Rinne und dem sogenannten Schwarzen Auenboden. Das Pollenbild ist von Gehölzarten (vor allem Kiefer und Hasel) dominiert. Entsprechende regionale Vegetationsaspekte der Lößflächen fehlen unter den Großresten. Elemente von Röhrichten und Seggenrieden langsam fließender oder stehender Gewässer sind hingegen in diesem wie auch den folgenden Zeitabschnitten gleichermaßen durch Pollen und Großreste erfaßt, wobei jedoch Arten einer Weichholzaue fehlen. Großreste eines Gehölzbestandes im Flußtal wurden ebenfalls nicht gefunden. 
Im spätboreal-frühatlantischen Horizont des sogenannten Schwarzen Auenbodens sind keine pflanzlichen Großreste vorhanden. Die Pollenerhaltung in Probe 11 war an der Grenze der Auswertbarkeit. Das Phänomen der schlechten Erhaltung organischen Materials in diesem Horizont hat sich in Hessen bereits in Profilen des HorloffTals (Wetterau) und des Lahn-Tals gezeigt (STOBBE 1996, URz 1995). Alles spricht dafür, daß der Schwarze Auenboden unter terrestrischen Bedingungen entstand oder zwischenzeitlich durch Grundwasserabsenkung trockengefallen ist. In diesem Zusammenhang sind auch die Fruchtfunde von Wildem Majoran, Arznei- oder Sand-Thymian, Feldsalat und Wiesen-Salbei von Interesse. Sie zeigen, daß es im Frühholozän trockene, lichtreiche Standorte im Wetter-Tal oder auf angrenzenden Flächen gegeben hat (Kap. 3.5).

In den Auenlehmen des Zeitabschnittes Ende Subboreal/Beginn Subatlantikum (Übergang Bronze-Eisenzeit) fanden sich unter den Großresten Elemente der Röhrichte, Seggenriede und Schlammuferfluren (Kap. 3.2 u. 3.3): In den 17 spätbronze- bis hallstattzeitlichen Proben von Bohrkern 3 (Oppershofen) konnten 27 Arten nachgewiesen werden. 14 Arten fanden sich in den zwei spätbronzezeitlichen Proben von Gambach (Bohrung 82) und elf Arten in den zwei latènezeitlichen Proben von Ober-Hörgern (Bohrung 6; vgl. Tab. 2).

Teils lückige Staudenfluren am Ufer der Wetter und an Viehlagerplätzen sind durch zwölf Arten (Großreste) erfaßt (Tab. 2). Zehn Taxa heutiger Trittrasen, Rasen, Wiesen oder Weiden kommen hinzu. Fünf Arten verweisen auf stickstoffreiche Standorte. Das Wetter-Tal wurde in diesem Zeitabschnitt im Umfeld der Bohrungen sicherlich intensiv beweidet. Schnittwiesen lassen sich mit den gefundenen Großresten nicht nachweisen.

Das Flußtal war noch nicht völlig gehölzfrei: Bei Gambach ist Erle, in Bohrkern 3 bei Oppershofen und in Bohrung 6 bei Ober-Hörgern sind Eiche und Schlehe unter den Großresten nachgewiesen. Ergänzend kommen fünf Arten zumindest waldnaher Standorte hinzu (Tab. 2).

In den bronzezeitlichen Proben der Bohrung 82 bei Gambach fehlten Kulturpflanzenreste oder andere eindeutige Elemente der Lößflächen. In Bohrkern 3 von Oppershofen (Bronze- bis Eisenzeit) traten hingegen ein verkohltes Gerstenkorn sowie ein unverkohlter Samen von Schlafmohn auf (Tab. 2). In den latènezeitlichen Proben der Bohrung 6 von Ober-Hörgern fanden sich ein Korn von Gerste, ein Spelzenrest von Dinkel oder
Emmer sowie zwei unbestimmbare Getreidekörner (alles verkohlt).

In dem an den Übergang Eisenzeit/Frühe Römische Kaiserzeit datierten, subatlantischen Abschnitt spiegeln die Pollenanalysen aus Bohrkern 2 die regionalen Gehölzarten, wie zum Beispiel Buche, Eiche und Hainbuche mit für diese Zeitstellung üblichen geringen Prozentsätzen wider. Durch Großreste ist an Gehölzen nur Birke erfaßt. Weitere Elemente der angrenzenden Lößflächen sind die pollenanalytisch nachgewiesenen Getreide und anderen Landwirtschaftsindikatoren. Der einzige durch Großreste belegte eindeutige Eintrag von den Lößflächen ist ein verkohltes Korn von Weizen.

Pflanzenarten von Feuchtwiesen oder -weiden und Bachuferfluren sind pollenanalytisch gut repräsentiert, unter den Großresten im Gegensatz zu früheren oder späteren Zeithorizonten aber nur mit wenigen Nachweisen (Kleine Brunelle, Wald-Simse). Nach den Großresten wurde das Flußtal in diesem Zeithorizont nicht so intensiv genutzt wie zuvor und wie später im Mittelalter (Tab. 2). Als Ruderalpflanzen eher trockener Standorte sind die Nachweise (Samen/Früchte) von Unechtem Gänsefuß, Bilsenkraut und Taubnessel zu interpretieren. Pollenanalytisch sind vor allem Chenopodiaceae mit hohen Werten erfaßt.

Interessanterweise fehlen in diesem und dem folgenden Zeitabschnitt unter den Großresten Hinweise auf Auwälder oder Erlenbrüche. Pollenanalytisch sind Weide und Erle nachgewiesen.

Im Zeithorizont Mittelalter wird das Pollenspektrum in Bohrkern 2 von Arten dominiert, die eine intensive Landwirtschaft in einer weitgehend entwaldeten Landschaft anzeigen (u. a. Roggen, Kornblume etc.). Eigenartigerweise fehlen hingegen unter den Großresten eindeutige Kulturzeiger der Lößflächen vollständig.

Andererseits sind unter den Großresten (Proben 16-26, Tab. 2) und den Pollenkörnern/Sporen Arten vertreten, die wiederum mit einer intensiven Nutzung des Wetter-Tales als Viehweide in Verbindung gebracht werden können. Das Spektrum enspricht weitgehend dem in den spätbronzeund eisenzeitlichen Bohrkernabschnitten. Neu treten an möglichen Uferpflanzen unter den Großresten Pfirsichblättriger Knöterich, Kratzbeere und Krauser oder Stumpfblättriger Ampfer auf (Tab. 2). Samen und Früchte von Gewöhnlichem Eisenkraut, Wiesen-Schafgarbe, Frühlings-Segge und Sumpfdotterblume stammen aus der Gruppe 
Trittrasen, Rasen, Wiesen oder Weiden. Ausgesprochene Schnittwiesenarten fehlen überraschenderweise auch hier.

An Gehölzen sind unter den Großresten nur Eiche (Holzkohle) und Schwarzer Holunder vertreten. Weitere Arten wuchsen wohl in Krautsäumen von Gebüschen (Tab. 2).

Das Fehlen von Kulturpflanzen, Acker- oder Gartenunkräutern unter den Großresten gibt einen Hinweis, daß die entsprechenden, zum Teil zahlreichen pollenanalytischen Nachweise dieses Abschnitts zumindest überwiegend einem Eintrag durch Wind zu verdanken sind. Dies ist besonders bemerkenswert, da es sich bei den untersuchten Sedimenten um Auenlehme handelt. Es stellt sich die Frage, warum Samen oder Früchte entsprechende Taxa nicht erosiv von den benachbarten, stark ackerbaulich genutzten Lößflächen in die Ablagerung gelangten. Das Fehlen solcher Kulturarten läßt annehmen, daß auch die fast durchgängig vorhandenen Holzkohlefragmente aus dem Wettertal stammen.

In dem 2,78 Meter mächtigen Auenlehmpaket im Auenquerprofil 2 von Ober-Hörgern (Abb. 3) wurde nur ca. 1 Meter bis zum Hochmittelalter abgelagert. Dabei gilt es allerdings zu bedenken, daß zwischen den römischen und mittelalterlichen Sedimenten möglicherweise ein Hiatus von mehreren hundert Jahren liegt und auch aus den Chronozonen Atlantikum und Subboreal kaum Sedimente vorhanden sind. Es fragt sich daher, ob sich das Phänomen der Auenlehmablagerung tatsächlich erst seit dem Hochmittelalter verstärkt hat.

Die Untersuchung zeigt, daß sich mit unterschiedlichen Informationsquellen aus Geomorphologie und Sedimentologie sowie mittels ${ }^{14} \mathrm{C}$ Datierungen, Pollenanalyse und der Untersuchung pflanzlicher Großreste trotz schwieriger Ablagerungs- und Erhaltungsbedingungen interessante Ergebnisse zur Vegetationsgeschichte und Kulturlandschaftsentwicklung der Flußtäler erzielen lassen. Eine gemeinsame Betrachtung von Pollenkörnern und pflanzlichen Großresten macht eine kontinuierliche Nutzung des Wettertales in vor- und frühgeschichtlicher Zeit wahrscheinlich.

\section{Mesolithische Besiedlungsspuren?}

(A. Kreuz)

Die in allen Zeitabschnitten angetroffenen Holzkohlepartikel (Tab. 3) sind im frühholozänen Bereich der Bohrkerne 1 und 2 (Ober-Hörgern) schwierig zu interpretieren. Nach häufig geäußer- ter Auffassung sind natürlich verursachte Waldbrände nur in sehr nadelholzreichen Wäldern zu erwarten, wie sie im Präboreal und frühen Boreal im Einzugsgebiet der Wetter noch zu erwarten sind (STOBBE 1996: u.a. 91-95). Andererseits muß im Mesolithikum mit anthropogenen Aktivitäten (Sammeln, Jagd usw.) gerechnet werden.

Ein auf nach ca. 8.090 BP (Frühes Atlantikum) datierter Moorbrand im östlich der Wetterau gelegenen Vogelsberg wird von SCHÄFER (1996: 167) in Zusammenhang mit Veränderungen zeitgleicher Pollenspektren als Hinweis auf Eingriffe spätmesolithischer Kulturgruppen in den Wald gedeutet. Mesolithische Besiedlungsspuren sind aus der nördlichen Wetterau von zwei den Bohrstellen nahegelegenen Fundplätzen bei Muschenheim und Münzenberg bekannt (frdl. Mitt. L. FIEDler, Landesamt für Denkmalpflege Hessen, Abt. Archäologische und Paläontologische Denkmalpflege, Außenstelle Marburg/Lahn).

Es fällt auf, daß verkohlte Fragmente von Halmknoten und Halmen von Gräsern nur in den frühholozänen Abschnitten der Bohrkerne 1 und 2 auftreten (gelegte Brände?). Neben (unverkohlten) Samen und Früchten einer differenzierten Ufervegetation konnten dort Arten erfaßt werden, die in trockenen Rasengesellschaften und lichten Wäldern wuchsen: Wilder Majoran, Arznei- oder Sand-Thymian, Wiesen-Salbei und Gezähnter Feldsalat (Tab. 2 u. 3). Gleichzeitig fanden sich Arten wie Rohrkolben, Wasserdost, Brennessel, Bittersüßer und Schwarzer Nachtschatten, Zottiges Weidenröschen und Wassermiere, die heute ausgesprochene Stickstoffzeiger darstellen (ELLENBERG 1979, OBERDORFER 1990). Diese Arten waren auf den noch stickstoffarmen Böden aus Löß kaum konkurrenzfähig. Im frühen Holozän sind stickstoffreiche Standorte nur in Verbindung mit Wildlägern oder in Auen mit hohem organischen (anthropogenen?) Eintrag zu erwarten.

Gerade flußnahe Standorte scheinen nach den archäologischen Funden der mesolithischen Existenzform entsprochen zu haben. So zeigte etwa die Aufarbeitung mesolithischer Altfunde im Main- und Rest-Neckarmündungsgebiet durch Gronenborn (1992: 36, Abb. 3) eine bevorzugte Lage solcher Plätze auf den Uferwällen der Mainund Neckaraltläufe. Dieses auch zum Beispiel aus den Niederlanden gut bekannte Phänomen müßte im Wetter-Tal mit interdisziplinären, archäologischen und naturwissenschaftlichen Untersuchungen noch weiter erforscht werden. 


\section{Schriftenverzeichnis}

Arora, S. K., Becker, W.-D., Boenigk, W., Bunnik, F.P.M., Päffgen, B., Kalis, A.J. \& Meurers-Balke, J. (1995): Eine frühmittelalterliche Talverfüllung im Elsbachtal, Rheinland (Frimmersdorf 114). - Bonner Jahrbücher 195: 251-297, 14 Abb.; Bonn.

BoHn, U. (1981): Vegetationskarte der Bundesrepublik Deutschland 1:200.000 - potentielle natürliche Vegetation, Blatt CC 5518 Fulda. - Schriftenreihe f. Vegetationskde. 25: 330 s.; Bonn-Bad-Godesberg.

Bunnik, F. P. M., Kalis, A. J., Meurers-Balke, J. \& Stobbe, A. (1995): Archäopalynologische Betrachtungen zum Kulturwandel in den Jahrhunderten um Christi Geburt. - Archäologische Informationen, 18/2: 169185, 4 Abb.; Bonn

Caspers, G. (1993): Vegetationsgeschichtliche Untersuchungen zur Flußauenentwicklung an der Mittelweser im Spätglazial und Holozän. - Abh. Westf. Mus. Naturkde, 55, 101 S., 38 Abb., 5 Tab., 2 Beil.; Münster.

DEUTSCHER WETTERDIENST (Hrsg.) (1950): Klimaatlas von Hessen; Bad Kissingen.

Dickson, J. H. (1986): Bryophyte analysis. - In: Berglund, B.E. [Hrsg.]: Handbook of Holocene Palaeoecology and Palaeohydrology. - S. 455-484; Chichester (John Wiley \& Sons).

EllenberG, H. (1979): Zeigerwerte der Gefäßpflanzen Mitteleuropas. - Scripta Geobotanica IX, 122 S., 8 Tab.; Göttingen.

- (1996): Vegetation Mitteleuropas mit den Alpen in ökologischer, dynamischer und historischer Sicht. 1096 S., 623 Abb., 170 Tab.; Stuttgart.

Filzinger, O. (1992): Geomorphologische Untersuchungen im Wetter-Tal und Horloffgraben. - Ber. d. Komm. f. Archäol. Landesforsch. in Hessen, 1 (1990/1991): 56-59, 4 Abb.; Büdingen.

Firbas, F. (1949): Spät- und nacheiszeitliche Waldgeschichte Mitteleuropas nördlich der Alpen. Band 1: Allgemeine Waldgeschichte. - 480 S.; Jena (Fischer).

Geel, B. van (1982/83): A Late Holocene Deposit under the Westfriese Zeedijk near Enkhuizen (Prov. of Noord-Holland. The Netherlands): Palaeoecological and Archaeological Aspects. - Rev. Palaeobot. Palynol., 38; 269-335; Amsterdam (Elsevier).

Gronenborn, D. (1992): Inventarwerk zu mesolithischen Fundplätzen im Main-Mündungsgebiet. Ber. d. Komm. f. Archäol. Landesforsch. in Hessen, 1 (1990/1991): 35-37, 4 Abb.; Büdingen.

Grosse-Brauckmann, G., Malchow, G. \&. Streitz, B. (1990): Makrofossil- und pollenanalytische Befunde vom Altneckarbett bei Riedstadt-Goddelau. - In: WAGNER, P. [Hrsg.]: Die Holzbrücken bei RiedstadtGoddelau, Kr. Groß-Gerau. - Materialien zur Vor- u. Frühgesch. v. Hessen, 5; 111-132, 8 Abb.; Wiesbaden.

HESSISCHES MINISTERIUM FÜR LANDWIRTSCHAFT UND FORSTEN [Hrsg.] (1968): Wasserwirtschaflicher Rahmenplan Nidda. - 158 S., 59 Ktn.; Wiesbaden.

Hiller, A., Litt, T. \& Eissmann, L. (1991): Zur Entwicklung der jungquartären Tieflandstäler im Saale-Elbe-Raum unter besonderer Berücksichtigung von ${ }^{14} \mathrm{C}$-Daten. - Eiszeitalter u. Gegenwart, 41: 26-46, 12 Abb., 1 Tab.; Hannover.
HuCKRIEDE, R. (1971): Über jungholozäne, vorgeschichtliche Lößumlagerung in Hessen. - Eiszeitalter u. Gegenwart, 22; 5-16; Öhringen/Württ.

JÄGER, K.-D. (1962): Über Alter und Ursachen der Auenlehmablagerung thüringischer Flüsse. - Prähist. Zeitschr., 40 (1/2): 1-59, 1 Beil.: Berlin.

Jahns, H.M. (1987): Farne, Moose, Flechten. - 256 S.; München (BLV Verlagsgesellschaft)

JockenHÖvel, A. (1994): Ausgrabungen in der Talauensiedlung „Riedwiesen" bei Frankfurt am MainSchwalheim. Untersuchungen zum mittelbronzezeitlichen Siedlungswesen im Rhein-Main-Gebiet. Fundberichte Hessen, 24/25 (1984/1985): 9-104, 43 Abb., 2 Beil., Wiesbaden.

KNörzer, K.-H. (1996): Pflanzentransport im Rhein zur Römerzeit, im Mittelalter und heute. - Decheniana, 149: 81-123, 7 Abb., 2 Tab, 3 Taf.; Bonn.

KorNeCK, D. \& Sukopp, H. (1988): Rote Liste der in der Bundesrepublik Deutschland ausgestorbenen, verschollenen und gefährdeten Farn- und Blütenpflanzen und ihre Auswertung für den Arten- und Biotopschutz. - Schriftenreihe für Vegetationskunde, 19: 210 S., 2 Abb., 11 Tab.; Bonn-Bad Godesberg.

Kreuz, A. (1990): Die ersten Bauern Mitteleuropas - eine Einführung in Umwelt und Landwirtschaft der Ältesten Bandkeramik. - Analecta Praehistorica Leidensia 23: 257 S., 82 Abb., 37 Tab.; Leiden.

- (1993a): Einheimische oder fremde Pflanzen? Überlegungen zur Herkunft „potentieller Unkräuter“ und ihrer Verbreitung zur Zeit der Bandkeramik. Archaeo-Physika, 13 (Festschrift K.-H. Knörzer): 23-33, 3 Abb., 3 Tab.; Köln.

- (1993b): Frühlatènezeitliche Pflanzenfunde aus Hessen als Spiegel landwirtschaftlicher Gegebenheiten des 5. bis 4. Jh. v. Chr. - Ber. d. Komm. f. Archäol. Landesforsch. in Hessen, 2 (1992/1993): 147170, 12 Abb.; Büdingen.

- (1995a): Landwirtschaft und ihre ökologischen Grundlagen in den Jahrhunderten um Christi Geburt: zum Stand der naturwissenschaftlichen Untersuchungen in Hessen. - Ber. d. Komm. Archäol. Landesforsch. Hessen, 3 (1994/1995): 59-91, 13 Abb.; Büdingen.

- (1995b): On-site and off-site data - interpretative tools for a better understanding of Early Neolithic environments. - In: H. KRolL, R. PASTERNAK [Hrsg.]: Res archaeobotanicae. Berichte des 9. Symposiums der International Workgroup for Palaeoethnobotany, 117-134, 10 Abb; Kiel.

LANG, G. (1994): Quartäre Vegetationsgeschichte Europas. Methoden und Ergebnisse. - 462 S., 177 Abb., 54 Tab; Jena, Stuttgart, New York (G. Fischer).

MÄCKEL, R. (1969): Untersuchungen zur jungquartären Flußgeschichte der Lahn in der Gießener Talweitung. - Eiszeitalter u. Gegenwart 20: 138-174, 18 Abb., 2 Tab., 4 Prof.; Öhringen.

Mangerud, J., Andersen, S. T., Berglund, B. E. \& Donner, J. J. (1974): Quaternary stratigraphy of Norden, a proposal for terminology and classification. - Boreas, 3: 109-128, 5 Tab.; Oslo.

Mangerud, J., Birks, H. J. B. \& JÄGer, K. D. (1982): Chronostratigraphical subdivisions of the Holocene: A review. - Striae, 16: 1-6. 
Mangerud, J., Birks, H. J. B. \& Jäger, K. D. (1982): Chronostratigraphical subdivisions of the Holocene: A review. - Striae, 16: 1-6.

Moore, P. D., WebB, J. A. \& Collinson, M. E. (1991): Pollen Analysis. - 2. Aufl., 216 S.; Oxford (Blackwell).

Needham, S. \& Mackirn, M. G. [Hrsg.] (1992): Alluvial Archaeology in Britain. - Oxbow Monograph 27, 277 S.; Oxford.

Nolte, S. (in Vorber.): Holozäne Auensedimente der Wetter als Indikator für die paläo-geoökologische Entwicklung der Wetterau (Hessen). - Diss. Frankfurt/Main.

Oberdorfer, E. (1990): Pflanzensoziologische Exkursionsflora. - 1050 S.; Stuttgart (Ulmer).

Rupp, V. [Hrsg.] (1991), Archäologie der Wetterau Aspekte der Forschung. - Wetterauer Geschichtsblätter, 40: $356 \mathrm{~S}$; Friedberg.

SABEL, K. J. (1982): Ursachen und Auswirkungen bodengeographischer Grenzen in der Wetterau (Hessen). - Frankfurter Geowiss. Arb., D3: 116 S., 19 Abb., 8 Tab., 6 Prof.; Frankfurt/Main.

- (1983): Die Bedeutung der physisch-geographischen Raumausstattung für das Siedlungsverhalten der frühesten Bandkeramik in der Wetterau (Hessen). - Prähistor. Zeitschr., 58: 158-172; Berlin.

SAILE, T. (1992): Archäologisches Kataster des nördlichen Wetteraukreises. - Ber. d. Komm. f. Archäol. Landesforsch. in Hessen, 1 (1990/1991): 27-34, 5 Abb.; Büdingen.

SCHÄFER, M. (1996): Pollenanalysen an Mooren des Hohen Vogelsberges (Hessen) - Beiträge zur Vegetationsgeschichte und anthropogenen Nutzung eines Mittelgebirges, - Dissertationes Botanicae, 265: 280 S., 61 Abb., 10 Tab; Berlin, Stuttgart (Cramer).
Schirmer, W. (1983): Die Talentwicklung an Main und Regnitz seit dem Hochwürm. - Geol. Jb., A 71: 1143; Hannover.

SCHRADER, L. (1978): Erläuterungen zur Bodenkarte von Hessen 1:25.000, Bl. 5518 Butzbach. - Wiesbaden.

STовве, A. (1995): Ein subatlantisches Pollenprofil aus der Horloffaue bei Unter-Widdersheim/Wetterau. Ber. d. Komm. f. Archäol. Landesforsch. in Hessen, 3 (1994/1995): 175-190, 8 Abb.; Büdingen.

- (1996): Die holozäne Vegetationsgeschichte der nördlichen Wetterau - paläoökologische Untersuchungen unter besonderer Berücksichtigung anthropogener Einflüsse. - Dissertationes Botanicae, 260: 216 S., 47 Abb., 21 Tab.; Berlin, Stuttgart (Cramer).

URz, R. (1995): Jung-Quartär im Auenbereich der mittleren Lahn. Stratigraphische und paläontologische Untersuchungen zur Rekonstruktion vergangener Flußlandschaften. - Diss. Univ. Marburg/Lahn, 198 S., 28 Abb., 3 Tab., 5 Taf.; Marburg/L.

van Zeist, W., Wasylikowa, K. \& Behre, K.-E. (1991): Progress in Old World Palaeoethnobotany. A retrospective view on the occasion of 20 years of the International Work Group for Palaeoethnobotany. 350 S.; Rotterdam, Brookfield (A. A. Balkema).

WILLERDING, U. (1962): Beiträge zur jüngeren Geschichte und Vegetation der Flußauen (Untersuchungen aus dem Leinetal bei Göttingen). - Flora, 149: 435476; Jena.

Manuskript eingegangen am: 